\title{
Supporting Cell Characteristics in Long-deafened Aged Mouse Ears
}

\author{
Elizabeth C. Oesterle ${ }^{1}$ and Sean Campbell ${ }^{1}$ \\ ${ }^{1}$ Virginia Merrill Bloedel Hearing Research Center, Department of Otolaryngology-Head and Neck Surgery, University of \\ Washington, Seattle, WA 98195, USA
}

Received: 19 November 2008; Accepted: 13 July 2009; Online publication: 31 July 2009

\begin{abstract}
Significant sensory hair cell loss leads to irreversible hearing and balance deficits in humans and other mammals. Future therapeutic strategies to repair damaged mammalian auditory epithelium may involve inserting stem cells into the damaged epithelium, inducing non-sensory cells remaining in the epithelium to transdifferentiate into replacement hair cells via gene therapy, or applying growth factors. Little is currently known regarding the status and characteristics of the non-sensory cells that remain in the deafened auditory epithelium, yet this information is integral to the development of therapeutic treatments. A single high-dose injection of the aminoglycoside kanamycin coupled with a single injection of the loop diuretic furosemide was used to kill hair cells in adult mice, and the mice were examined 1 year after the drug insult. Outer hair cells are lost throughout the entire length of the cochlea and less than a third of the inner hair cells remain in the apical turn. Over $20 \%$ and $55 \%$ of apical organ of Corti support cells and spiral ganglion cells are lost, respectively. We examined the expression of several known support cell markers to investigate for possible support cell dedifferentiation in the damaged ears. The support cell markers investigated included the microtubule protein acetylated tubulin, the transcription factor Sox2, and the Notch signaling ligand Jagged1. Non-sensory epithelial cells remaining in the organ of Corti retain acetylated tubulin, Sox2
\end{abstract}

Correspondence to: Elizabeth C. Oesterle - Virginia Merrill Bloedel Hearing Research Center, Department of Otolaryngology-Head and Neck Surgery - University of Washington - Seattle, WA 98195, USA. Telephone: +1-206-6162705; fax: +1-206-2215685; email: oesterle@u. washington.edu and Jagged1 expression, even when the epithelium has a monolayer-like appearance. These results suggest a lack of marked SC dedifferentiation in these aged and badly damaged ears.

Keywords: dedifferentiation, ototoxicity, aminoglycoside, cochlea, hair cell

Abbreviations: HC - hair cell; IHC - inner hair cell; $\mathrm{OHC}$ - outer hair cell; SC-supporting cell; SEsensory epithelium

\section{INTRODUCTION}

Auditory hair cells (inner hair cells, IHCs, and outer hair cells, OHCs) which reside in the organ of Corti in the inner ear are mechanoreceptors that detect environmental signals associated with hearing. A variety of nonsensory support cells (Hensen, Deiters', inner pillar, outer pillar, inner phalangeal, and border cells) reside in the organ along with the HCs. Type I and type II spiral ganglion neurons, the primary afferent neurons of the cochlea, have their cell bodies in Rosenthal's canal in the modiolus of the cochlea, and they form synaptic contacts with the HCs via their peripheral processes and transmit information to the central auditory pathways, leading to the perception of sound.

Hair cells are killed by variety of mechanisms, including loud sounds, ototoxic drugs, and aging, and hearing functions deteriorate as HCs are lost. Because auditory HCs are not regenerated in mature mammals (Sobkowicz et al. 1992; Roberson and Rubel 1994; Chardin and Romand 1995), significant HC loss leads to secondary loss of spiral ganglion cells and irreversible hearing deficits. As the HCs degenerate, the support cells (SCs) expand and form scars 
preventing fluid mixing and maintaining the epithelium (Bohne 1976; Hawkins and Johnson 1981; Bohne and Rabbitt 1983; Forge 1985; Raphael and Altschuler 1991). The damaged epithelium can also transition to flat or simple cuboidal epithelium (Pawlowski et al. 2006; Kim and Raphael 2007; Izumikawa et al. 2008). Future therapeutic strategies to repair damaged mammalian auditory epithelium may involve inserting stem cells into the damaged epithelium, inducing SCs remaining in the epithelium to transdifferentiate into replacement $\mathrm{HCs}$ via gene therapy, and/or applying growth factors to stimulate the mitotic production of new sensory epithelial cells. Some therapeutic approaches will likely involve manipulations of aged, long-damaged ears, yet little is known about the non-sensory cells that remain in these ears. Understanding the characteristics of the non-sensory cells that remain after HC loss will be integral to the development of therapeutic strategies.

Recently, we developed an in vivo model of the aminoglycoside-damaged adult mouse organ of Corti to gain access to the unparalleled capacity for genetic manipulation in mice to investigate different aspects of cochlear pathology, repair, and recovery (Oesterle et al. 2008). The lesion, induced with a combination of a single dose of the aminoglycoside kanamycin followed by a single dose of the loop diuretic furosemide, results in rapid loss of virtually all OHCs throughout the entire cochlea by 3 days. Given the need to better understand the characteristics of nonsensory cells in aged long-damaged ears, the aims of the study were: (1) to further characterize our in vivo drug-damaged model system and delineate the lesion characteristics at 1 year of recovery and (2) to examine the morphological characteristics of the non-sensory cells remaining in the organ of Corti 1 year after insult and investigate for possible SC dedifferentiation. The latter was accomplished by examining the expression of three known SC-specific markers: acetylated tubulin - a tubulin isoform present normally in mature pillar and Deiters' cells, Sox2-a transcription factor of the SRY-related HMG box (SOX) family expressed normally in mature organ of Corti SCs, and Jagged 1 - a member of the Notch signaling pathway expressed normally in organ of Corti SCs. Animal studies with survival times of a year or more are rare, hence, the qualitative and quantitative analysis presented here provide unique insight into long-term sequelae of $\mathrm{HC}$ loss in the adult mouse organ of Corti. These data show that: (1) virtually all OHCs are missing and less than one third of the IHCs remain 1 year after insult, (2) support cell numbers are decreased, but marked SC dedifferentiation is not seen as evidenced by retention of acetylated tubulin, Sox2, and Jagged1 labeling in these cells 1 year after insult, and (3) over $40 \%$ of the spiral ganglion neurons survive and nerve fibers can remain, especially in the habenular region, when both IHC and OHCs are missing 1 year after insult.

\section{MATERIALS AND METHODS}

\section{Animals}

The Institutional Animal Care and Use Committee (IACUC) at the University of Washington approved experimental methods and animal care procedures. Adult outbred Swiss Webster mice were purchased from Harlan (Indianapolis, IN) or Charles River (Wilmington, MA). They were sacrificed by cervical dislocation or by anesthesia with $\mathrm{CO}_{2}$ followed by decapitation.

\section{Drug-lesioning paradigm}

Hair cell death was experimentally induced in eight adult (3-4 months old) mice by administering single doses of kanamycin $(1,000 \mathrm{mg} / \mathrm{kg}$, dissolved in phosphate-buffered saline (PBS), Sigma-Aldrich Co., St. Louis MO, Cat. No. K-1377, subcutaneous) followed 30-45 min later by a single dose of furosemide (400 mg/kg, Hospira Inc., Lake Forest IL, Cat. No. RL-1206, intraperitoneal). Seven of the animals were sacrificed 1 year after injection, one animal was sacrificed at 10 months. For the animals sacrificed 1 year after injection, one ear was prepared as wholemount preparations for immunofluorescence, and the second ear was prepared for frozen or plastic sections. For the animal sacrificed at 10 months, one ear was prepared for phalloidin labeling and the second for immunofluorescence. In the majority of experiments, adult animals 1 year in age, not injected with the drug combination, were used as controls. In some experiments, non-injected adult animals $4-5$ months of age were used as controls.

\section{Tissue preparation}

The temporal bones were dissected free. After removal of the bulla, the stapes was lifted from the oval window, and small openings were made in the apical and basilar turns. For experiments involving immunofluorescence processing, cold $4 \%$ paraformaldehyde in $0.1 \mathrm{M}$ phosphate buffer, $\mathrm{pH}$ 7.4, was perfused slowly through the cochlea, after which the temporal bones were kept in the same fixative for $4 \mathrm{~h}$ at room temperature. Following fixation, the temporal bones were washed three times $(10 \mathrm{~min}$ each) in PBS (pH 7.4). The tissue was prepared as wholemount preparations or cryostat sections (Oesterle et al. 1990). For the former, segments (half turns) of the organ of Corti were carefully dissected free from the 
cochlea. The stria vascularis was pulled off or trimmed down, and the tectorial membrane was lifted free with fine forceps and then discarded. For cryosections, the temporal bones were decalcified with RDO Rapid Decalcifier (Apex Engineering Products Corp., Aurora, IL) at room temperature for $15 \mathrm{~min}$, rinsed in PBS, and sequentially infiltrated with sucrose $(10 \%$ for $30 \mathrm{~min}, 15 \%$ for $30 \mathrm{~min}, 1: 1 \mathrm{mix} 15 \%$ sucrose/O. C.T. overnight) and O.C.T. compound (Tissue Tek, Sakura Finetek Inc., Torrance, CA), frozen rapidly with dry ice, and cut into $12-\mu \mathrm{m}$ sections with a cryostat. Sections were mounted onto Platinum Superfrost $(+)$ slides (Mercedes Medical).

Two ears from different drug-damaged animals (1-year recovery) and two ears from different normal control animals were prepared for plastic embedding and sectioning. For this, an intralabyrinthine perfusion was performed with $3.5 \%$ glutaraldehyde in $0.1 \mathrm{M}$ potassium phosphate buffer $(\mathrm{pH} 7.4)$, and the temporal bones were immersed in this fixative overnight at $4^{\circ} \mathrm{C}$. After washes with PBS, the ears were decalcified with RDO Rapid Decalcifier at room temperature for $15 \mathrm{~min}$, rinsed in PBS, and dehydrated in a graded ethanol series (35\% for $15 \mathrm{~min}, 70 \%$ overnight, $95 \%$ for $15 \mathrm{~min}, 100 \%$ for $15 \mathrm{~min})$. Tissues were then incubated in propylene oxide, prior to embedding in Eponate 12 resin (Ted Pella Inc., Redding, CA). Semithin sections were cut at a thickness of $2 \mu \mathrm{m}$ through the organ and mounted onto acid-washed, chrome-alum-subbed slides. Slides were counterstained with $1 \%$ toluidine blue before coverslipping with DPX mounting medium.

\section{Antibodies}

Two antibodies were used to label HCs, a mouse monoclonal anti-parvalbumin antibody (parv19, Cat. No. P3088, Sigma, St. Louis MO, 1:1,000; Sage et al. 2000) and a rabbit anti-pig myosin VI polyclonal antibody (from Dr. Tama Hasson, UC-San Diego, or Proteus Biosciences, Ramona, CA, Cat. No. 25-6791, 1:500; Hasson and Mooseker 1994; Hasson et al. 1997). These antibodies have been used previously to label HCs in mice and other mammals (e.g., Hasson et al. 1997; Sage et al. 2000; Montcouquiol and Kelley 2003; Hackney et al. 2005; Oesterle et al. 2008). To label nerve cell bodies and fibers, a polyclonal chicken anti-neurofilament-heavy antibody (Chemicon, Cat. No. AB5539) was used at 1:5,000.

An affinity-purified goat polyclonal antibody directed against the $\mathrm{C}$ terminus of human Sox2, was purchased from Santa Cruz (Sox-2 Y-17, Cat. No. SC17320, Santa Cruz, CA). The Sox2 antibody was used routinely at dilutions of 1:500-1:1,000. Specificity of the antibody was verified in an earlier study by blocking with a Sox2-specific peptide and eliminating all labeling (Hume et al. 2007). The Sox2 antibody stains a single band of $37-40 \mathrm{kD}$ on Western blot (manufacturer's technical information).

To detect Jagged1, an affinity-purified goat polyclonal antibody raised against the $\mathrm{C}$ terminus of human Jagged1 was purchased from Santa Cruz Biotechnology, Inc. (Jagged1 (C-20), Cat. No. SC-6011) and used at dilutions of 1:100 to 1:1,000. Jagged1 (C-20) has been used previously in mouse inner ear (Morrison et al. 1999; Chen et al. 2002; Brooker et al. 2006; Oesterle et al. 2008), and Western blot analyses carried out by the manufacturer on murine samples demonstrated that this antibody does not cross react and recognizes a single protein of the correct size ( $150 \mathrm{kD} \mathrm{MW})$.

A monoclonal anti-acetylated tubulin was purchased from Sigma (Clone 6-11B-1, Cat. No. T6793) to detect acetylated tubulin and used at a dilution of 1:250. This antibody has been used to detect acetylated $\alpha$-tubulins from many organisms including mouse (e.g., MacDonald and Rubel 2008).

\section{Immunofluorescent labeling}

The tissue was treated for $30 \mathrm{~min}$ with $0.1 \%$ saponin/ $0.1 \%$ Tween 20 in PBS in order to make membranes more permeable to antibodies. To prevent nonspecific binding of the primary antibody, tissues were then incubated for $1 \mathrm{~h}$ in a blocking solution consisting of $10 \%$ normal serum $/ 0.03 \%$ saponin/ $0.1 \%$ Triton X-100 in PBS. Primary antibody incubations were performed for 1 day at $4^{\circ} \mathrm{C}$ in PBS, $0.03 \%$ saponin, 3\% serum, $2 \mathrm{mg} / \mathrm{ml}$ bovine serum albumin, and $0.1 \%$ Triton $\mathrm{x}-100$. Fluorescent-labeled secondary antibodies (Alexa 488, 568, 594, 647, Invitrogen/ Molecular Probes) were used at a dilution of 1:200 in the same buffer for 2-4 h (at room temperature) or overnight (at $4^{\circ} \mathrm{C}$ ). In some cases (for myosin VI), the TSA system (Invitrogen/Molecular probes) was used for signal amplification as recommended by the manufacturer. For mouse antibodies against parvalbumin, the Mouse-on-Mouse kit (M.O.M.) was used as specified by the manufacturer (Vector Labs). Sections were washed after each antibody incubation (three times for $10-15$ min each) in $0.1 \%$ Tween 20 in PBS. After counterstaining nuclei with DAPI (Cat. No. D9542, Sigma-Aldrich, $1 \mu \mathrm{m} / \mathrm{ml}$ ) or YO-PRO-1 (Cat. No. Y3603, Invitrogen Corp., Eugene OR, 1:200), specimens were mounted in Vectashield (Vector Laboratories), coverslipped, and examined with either epifluorescence or confocal fluorescence microscopy.

\section{Controls for immunofluorescence}

Method and antibody specificity were checked by: (1) substituting nonimmune sera for the primary antibody, (2) using a series of dilutions of the primary 
antibody; and (3) processing positive control tissues alongside the adult inner ear tissue. In double-labeling experiments, antibodies raised in different species were used to avoid cross reactivity among secondary antibodies.

\section{Phalloidin labeling}

Phalloidin labels F-actin. To visualize HC stereociliary bundles, cuticular plates, and SC scars, phalloidin conjugated to a fluorophore (Alexa 594, Invitrogen Corp. Eugene, OR, Cat. No. A12381) was added to whole-mount preparations of isolated inner ear end organs at a concentration of 5 units/ml (approximately $0.165 \mu \mathrm{M}$ ). After a 30 -min incubation at room temperature, the tissue was washed in PBS (3x $10 \mathrm{~min}$ ), mounted on a microscope slide in Vectashield, and examined with confocal microscopy.

\section{Microscope imaging}

Whole-mount preparations and cryostat sections were viewed with an Olympus FV-1000 laser scanning confocal microscope, equipped with $405 \mathrm{~nm}$ blue diode; 457, 488, and $514 \mathrm{~nm}$ multiline argon; $543 \mathrm{~nm}$ helium neon green; and $637 \mathrm{~nm}$ helium neon red lasers. Fluoview version 1.4a acquisition software was used. Sequential image acquisition was performed when bleed-through between channels was an issue. Files were imported into Image $1.42 \mathrm{a}(\mathrm{NIH})$ and/or Adobe Photoshop CS version 8 (Adobe, Seattle, WA) for processing and analysis. Histogram stretches were performed with Photoshop as necessary to fill the dynamic range.

Plastic-embedded sections were viewed on a Zeiss Axioplan 2ie compound microscope, and images were captured with a Photometrics CoolSNAP hq digital camera (Image Processing Solutions, North Reading, MA). Slidebook 4.0.1.40 (Intelligent Imaging Innovations, Denver, CO) acquisition and processing software was used to acquire digital images and convert them to tagged image file format (TIFF) files. TIFF files were subsequently processed in Adobe Photoshop and histogram stretches were performed as necessary.

\section{Estimation of $\mathrm{HC}$ and SC numbers in whole-mount preparations}

Whole-mount preparations of apical turns taken from five drug-damaged (1-year recovery) and four normal control ears were double-labeled to detect organ of Corti SCs and HCs by labeling for Sox2 and myosin VI or Sox2 and parvalbumin and counterstained with DAPI. They were examined with an Olympus FV-1000 confocal laser scanning microscope. Digital images were generated from $\mathrm{Z}$ series $(1 \mu \mathrm{m}$ steps oriented parallel to the lumen) through the sensory epithelium $(\mathrm{SE})$ at $\times 60(\times 20$, zoom $=3)$ or $\times 100(\times 20$, zoom $=5)$. Four confocal $\mathrm{Z}$ series were randomly collected from each apical turn. The area of each sampled region was quantified with Image $\mathrm{J}$ and equaled $0.045 \mathrm{~mm}^{2}$. Density estimates of the number of Sox2-positive SC nuclei and myosin VI-positive or parvalbumin-positive HCs were determined for each sampled region using the Cell Counter plug-in for ImageJ by dividing the number of Sox2-positive SCs, myosin VI-positive HCs, or parvalbumin-positive HCs by $0.045 \mathrm{~mm}^{2}$. Average numbers were determined for each organ and mean values were computed for each paradigm.

\section{Spiral ganglion cell counts}

Spiral ganglion cell counts were obtained for the cochlear apex and base in plastic sections collected from six drug-damaged (1-year recovery, $n=2$; 30-day recovery, $n=4$ ) and two control animals. To enable a comparison between a long and short survival time, counts were obtained from plastic sections collected from 30-day recovery animals used in a previous study that were prepared identically to the ones in this study (Oesterle et al. 2008). Five mid-modiolar sections of each ear were viewed on a Zeiss Axioplan 2ie compound microscope with $\mathrm{a} \times 40$ objective lens, and digital images were collected of the spiral ganglion region in the cochlear apex and base of each section. The spiral ganglion region in Rosenthal's canal was outlined, and its area was computed using ImageJ. Using the Cell Counter plug-in, all spiral ganglion neurons within the outlined region were counted. The criteria for a neuron to be counted were a welldefined cytoplasm and nuclear outline and clearly visible nucleoli. Spiral ganglion cell density was calculated by dividing the number of spiral ganglion cells by the area measured. Average values were determined for each ear, and percentage changes were computed for experimental versus control animals.

\section{Assessment of stria vascularis thickness}

Digital images of the stria vascularis in plastic-embedded sections were taken at $\times 40$ on a Zeiss Axioplan 2ie compound microscope. For each ear, images of the stria were obtained from both the apical and basal turns in six sections. Measurements of the thickness, from the endolymphatic surface of the marginal cells to the spiral ligament side of the basal cells, were made at the central thickest portion of the stria. Measurements were collected at 1 year of recovery $(n=$ 2 ) and from control cochleas $(n=2)$. To facilitate comparisons with shorter recovery times, measure- 
ments were similarly collected from plastic sections of 30 day $(n=2)$ and 80 day $(n=2)$ recovery animals used in an earlier study (Oesterle et al. 2008) that were prepared identically to the ones in this study.

\section{Statistics}

Significance values were determined with the Student's test (Excel) or an ANOVA with a Bonferroni post-hoc test (Prism, GraphPad Software).

\section{RESULTS}

\section{HC-specific markers}

Parvalbumin (Fig. 1A, B), a $\mathrm{Ca}^{2+}$-binding protein, and myosin VI (Fig. 1J, K) are selectively expressed in inner ear HCs (Dechesne et al. 1994; Hasson et al. 1995, 1997; Zheng and Gao 1997; Hackney et al. 2005). Parvalbumin is also observed in nerve terminals, nerve fibers, and the spiral ganglion (SG) cell bodies located within the modiolus. It was verified in our previous study that the loss of the HC markers parvalbumin or myosin VI is indicative of HC loss (Oesterle et al. 2008). Parvalbumin was used in the current study, because it simultaneously provides information regarding $\mathrm{HC}$ presence and neural innervation patterns in the organ of Corti. Myosin VI was used to identify HCs in some double- or triplelabeling experiments to avoid using antibodies raised in the same species and to prevent cross reactivity among secondary antibodies.

\section{Extensive $\mathrm{HC}$ loss with some SC loss is seen} 1 year after drug insult

To characterize the non-sensory cells in the cochlea of aged long-damaged ears, we drug-damaged seven adult (3-4 months old) mice with kanamycin and furosemide and allowed them to survive for 1 year before processing their ears for immunocytochemistry or embedding in plastic. Mice typically have an average lifespan of 2 years. Therefore, our histological examination fell near the start of the final third of their natural lifespan. One ear from each of the seven drug-damaged animals was microdissected and processed as whole-mount preparations for Sox $2 /$ myosin VI/neurofilament triple labeling $(n=3)$, Sox2/parvalbumin double labeling $(n=2)$, or Jagged1 labeling $(n=2)$. All of these ears were also counterstained with the nuclear marker DAPI. The second ear from each of these animals was embedded in plastic $(n=2)$ or frozen and cryo-sectioned before immunocytochemistry $(n=5)$ to enable examination of transverse sections of the cochlea. One additional adult mouse was damaged with kanamycin and furosemide and allowed to survive for 10 months before processing its ears for myosin VI/acetylated tubulin double labeling or phalloidin labeling. Ears from control animals were similarly processed as whole-mount preparations and cryostat sections for immunocytochemistry or embedded in plastic before sectioning.

The kanamycin/furosemide drug-injection protocol kills nearly all OHCs throughout the cochlea by $2-$ 3 days, but large numbers of IHCs remain at 11 weeks of recovery (Oesterle et al. 2008). In contrast, at 10 months or 1-year post drug treatment marked IHC loss accompanies the OHC loss seen previously in $87 \%$ (seven of eight) of the drug-injected animals studied. To illustrate, low magnification images of apical turns taken from a normal control animal and three drug-damaged mice at 1 year of recovery and immunostained for a $\mathrm{HC}$ marker, parvalbumin or myosin VI, are shown in Figure 1. IHCs persist individually, in small clusters, or in larger groups with spotty loss in two of the drug-injected animals shown (Fig. 1D, G). Small stretches of these organs have total IHC loss and OHCs are essentially absent throughout these ears. In one of the eight drug-injected animals, only occasional IHCs are lost in the apical (Fig. 1J) and middle turns, along with the virtually complete OHC loss.

High magnification images of surviving IHCs are included in Figure 1 to illustrate their condition. IHCs with relatively normal appearing body shapes and nuclear characteristics are seen (Fig. 1E, F). Displaced IHCs (abnormally low in the epithelium or peripheral to their HC row) and IHCs with abnormal body shapes and "ghost-like" immunolabeling, but normal nuclear characteristics, are also seen (Fig. 1H, I). Stereocilia bundles are discernable on the lumenal surface of the majority of surviving IHCs (Fig. 1N). Some bundles are abnormal with missing or elongated stereocilia (data not shown).

The extent of the HC loss was quantified in apical turns taken from five drug-damaged and four undamaged control animals immunolabeled for parvalbumin and Sox2 or myosin VI, Sox2 and neurofilament. It was not quantified for the middle or basal turns, because it is particularly difficult to perform fine dissections on these regions of the mouse cochlea and to obtain large stretches of epithelium needed for the analyses. The numbers of parvalbumin- or myosin VIlabeled IHCs, OHCs, and Sox2-labeled SCs for each apical turn were counted and expressed as a function of sensory epithelial area. Mean values $( \pm$ the SD) are given in Table 1 . Just $8 \%$ of the HCs remain at 1 year. Virtually all OHCs are absent $(0.9 \%$ remain) and less than one-third $(30.3 \%)$ of the IHCs persist. Fewer SCs are present in the organ 1 year after the drug treatment; $78.1 \%$ of the Sox2-positive cells remain (controls, 7,247.6 Sox $2^{+}$cells $/ \mathrm{mm}^{2} \mathrm{SE} \pm 421 \mathrm{SD}$; 1-year 
recovery, 5,691.1 \pm 785$)$. SCs within the damaged epithelium did not lose Sox2 labeling, because 100\% of the Sox2-negative cells seen in the sensory epithelium were labeled with a HC marker (parvalbumin or myosin VI). Sox2-negative/HC marker-negative cells were not detected in the damaged organ of Corti 1 year after insult.

\section{Organ of Corti architecture retains some normal characteristics 1 year after treatment, in spite of extensive $\mathrm{HC}$ loss}

An examination of plastic-embedded ears reveals that the architecture of the organ of Corti is disturbed but retains some normal characteristics, i.e. retains a tunnel of Corti, 1-year post drug injection in spite of extensive HC loss. This is shown in Figure 2 with photomicrographs of plastic sections taken from the apical (panels A and B) and basal (panels C and D) turns of a drug-damaged animal killed 1 year after the drug treatment. Inner and outer HCs are missing, yet the tunnel of Corti remains intact, even in the basal turn. Border, inner phalangeal, and Deiters' cells are apparent, although nuclear positions have shifted. Deiters' and Hensen cells have changes in shape. At the light microscopic level, the morphological appearance of the inner and outer pillar cells resembles that of normal control animals, and distinctive intracellular filament bundles are still prominent in these cells. Similar bundles are apparent in remaining Deiters' cells (arrow in Fig. 2A, C). As discussed below, phalloidin-labeled and acetylated tubulin-labeled bundles are present within remaining Deiters' and pillar cells 10 months or 1 year after drug treatment.

\section{Molecular characteristics of SCs are retained \\ 1 year after insult, suggesting an absence of marked dedifferentiation}

The expression of three known SC markers, namely, acetylated tubulin, Sox2, and Jagged 1 was studied in the kanamycin/furosemide-treated animals 1 year after the injections to examine for SC dedifferentiation after drug damage. Two of the markers, acetylated tubulin and Sox2, were also examined in a drug-treated animal with a 10-month recovery.

\section{Acetylated tubulin}

Acetylated tubulin is a tubulin isoform that is found along the length, or in specific regions of, stable microtubules (Thompson et al 1984; L'Hernault and Rosenbaum 1985; LeDizet and Piperno 1986; CambrayDeakin and Burgoyne 1987). Acetylated tubulin is expressed in pillar and Deiters' cells in the normal mature organ of Corti (Fig. 3C, D) and is thought to be a component of the prominent intracellular actin-
FIG. 1. Hair cells are lost after the drug insult. Confocal images are shown of whole-mount preparations of the apical turn of normal control (no drug exposure) adult mice (A-C, $\mathbf{M}$ ) and kanamycin/ furosemide-injected mice sacrificed 1 year $(\mathbf{D}-\mathbf{L})$ or 10 months $(\mathbf{N}$ and $\mathbf{O})$ after drug insult. The tissue is immunolabeled with the HCmarker parvalbumin (A-I) or myosin $\mathrm{VI}(\mathbf{J}-\mathbf{L})$, and nuclei are counterlabeled with DAPI. The top four rows show images from four animals, one animal per row. A low-magnification image of the $\mathrm{HC}$ labeling is shown on the left. The region indicated by the asterisk is shown at higher magnification in the middle and right panels, where a brightest point projection from a Z series spanning the $\mathrm{HC}$ layer is shown. Two channels are included in the middle panel; the green channel is parvalbumin or myosin $\mathrm{VI}$ labeling and the blue channel is DAPI staining. The DAPI channel alone is shown in the right panel. A-C A 1-year-old, non-drug injected, control mouse immunolabeled with parvalbumin. Parvalbumin labels the cytoplasm of inner hair cells (IHCS) and outer hair cells (OHCS) and spiral ganglion cell bodies (SG). Occasional OHCs are absent. D-I Two kanamycin/furosemide-injected mice with marked IHC loss 1-year post-injection. Virtually all $\mathrm{OHCs}$ and most IHCs are missing. Surviving IHCs can have a relatively normal morphological shape (E) with normal appearing nuclei $(\mathbf{F})$, or an abnormal shape or light label $(\mathbf{H})$ with normal nuclear characteristics (I). Arrows in $\mathbf{H}$ and $\mathbf{I}$ point to remaining IHCs, two have very light parvalbumin labeling. J-L A kanamycin/furosemide-injected mouse with many surviving IHCs 1-year post-injection. In one of seven animals studied 1-year post-injection, the animal shown here, many IHCs remain. A few OHCs (small arrows in $\mathbf{J}$ ) are present. M Phalloidin-labeled apical turn of a non-drug exposed, 1-year-old, control animal. A brightest point projection of a confocal stack spanning the lumenal portion of the HCs is shown. Stereociliary bundles and cuticular plates are labeled. $\mathbf{N}$ and $\mathbf{O}$ Phalloidin-labeled apical turn from a kanamycin/ furosemide animal 10-months post-injection. A brightest point projection of a Z-series spanning the IHC stereocilia is shown in panel N. Stereocilia bundles are present on surviving IHCs. Panel $\mathbf{O}$ shows a brightest point projection from a larger confocal stack of the same region that spans the lumenal surface of the organ. Prominent scars are visible in the upper region of the figure, the area formerly occupied by OHCs. The single and double asterisks delineate a missing IHC and pillar cell, respectively. Scale bars in panels A, D, $\mathbf{G}$, and J equal $200 \mu \mathrm{m}$. Scale bars in the right panels equal $10 \mu \mathrm{m}$ and also apply to the corresponding middle panel. EA extreme apex.

microtubule bundles in the cytoplasm of these cells (Tannenbaum and Slepecky 1997; Saha and Slepecky 2000). Prominent phalloidin-labeled F-actin bundles are apparent in these same cell types (data not shown).

Acetylated tubulin-labeled Deiters' and pillar cells were apparent in all drug-damaged animals examined, at 10 months and 1-year recovery. Cryostat sections taken from two drug-damaged cochlea immunolabeled for acetylated tubulin are shown in Figures 3A, B and 4. Figure 3 shows the retention of acetylated-tubulin labeling in Deiters' cells (arrow) in regions with no surviving HCs. This finding is further illustrated in a cochlea from the most severely damaged animal observed in the study, an animal where the organ of Corti thinned in the mid region to approach a monolayer or flat epithelium (Fig. 4). Acetylated-tubulin labeling is seen in all turns of the cochlea in this animal, even the mid region (panel B). Other sections from this ear show the same morphological pattern, thinned mid 

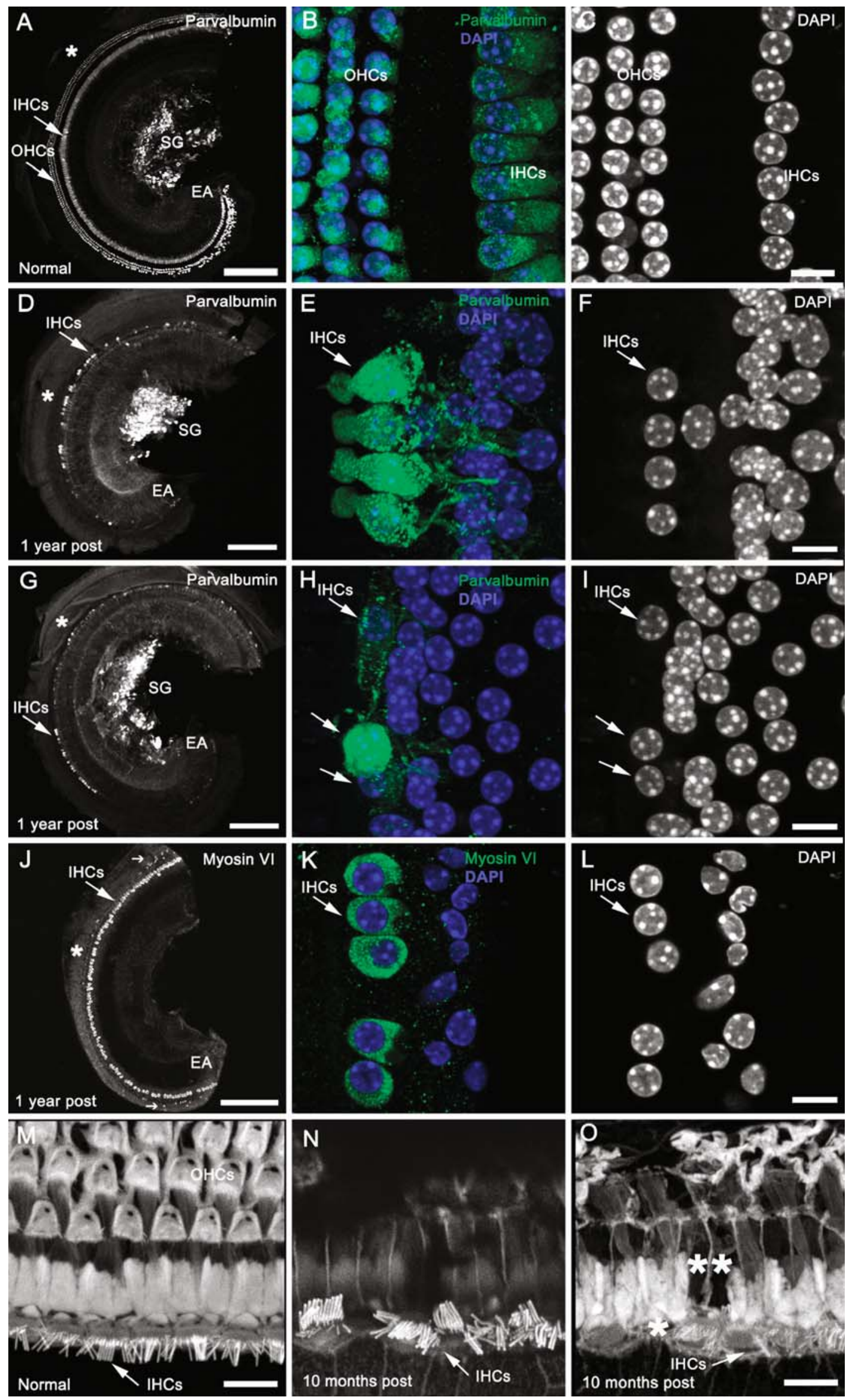


\section{TABLE 1}

HC and SC density in the apical turn 1 year after drug insult (number cells $/ \mathrm{mm}^{2} \mathrm{SE}$ )

\begin{tabular}{lcc}
\hline & Normal $^{a}(n=6)$ & Drug-damaged $(n=5)$ \\
\hline OHCs & $1,815.9 \pm 151.1$ & $16.7^{\mathrm{b}} \pm 45.5$ \\
IHCs & $582.0 \pm 46.9$ & $178.9^{\mathrm{b}} \pm 143.9$ \\
SCs & $7,247.6 \pm 421.2$ & $5,691.1^{\mathrm{b}} \pm 784.9$ \\
\hline
\end{tabular}

Mean values $\pm S D$

SE sensory epithelium

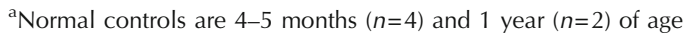

${ }^{\mathrm{b}}$ Significance from controls at the 0.001 level

region but clear tunnel retention in the base and apex. The presence of this pattern in multiple sections with good cut angle (inset panel B) suggests the monolayerlike appearance is not an artifact of cryosectioning.

Acetylated-tubulin labeling was similarly observed in whole-mount preparations of the drug-damaged organ of Corti in both Deiters' cells and pillar cells (data not shown). The highly ordered arrangement of the acetylated tubulin-labeled processes in the Deiters' cells in the undamaged organ of Corti is disturbed in the drug-damaged animals. Movement and repositioning of the intracellular bundles has occurred, especially in the lumenal-most regions.

\section{Sox2}

Sox2, a SRY-related HMG box transcription factor and a member of the Group B subgroup of Sox genes (Sox1, Sox2, Sox3), is involved in neurogenesis and the proliferation and/or maintenance of stem cells (reviewed in Episkopou 2005; Wegner and Stolt 2005). Sox2 is expressed in the nuclei of all SC subtypes in the normal adult mouse organ of Corti and in kanamycin/furosemide-damaged ears at 2 and 7 days of recovery (Oesterle et al. 2008). Sox2 expression was examined 1 year after drug treatment, and as demonstrated in Figure 5, Sox2 expression is maintained in the nuclei of all SC subtypes

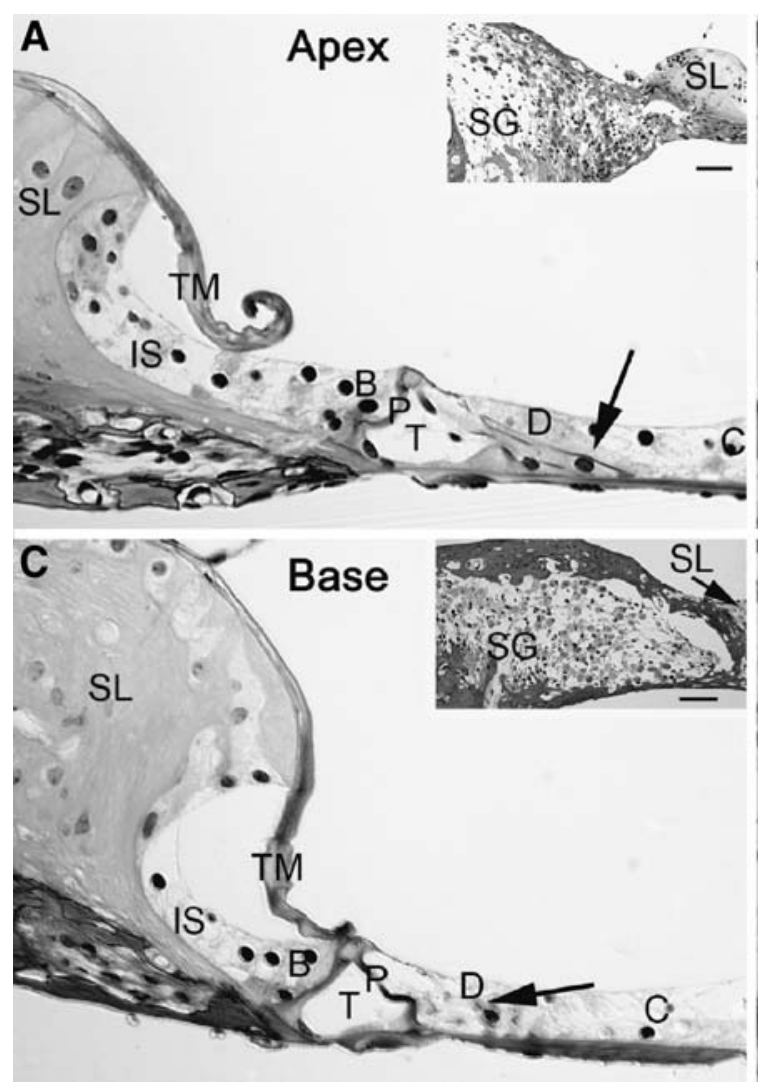

FIG. 2. Pillar cells and the tunnel of Corti are retained 1 year after insult, in spite of extensive HC loss. Photomicrographs of plasticembedded, toluidine blue-stained sections of adult mouse organ of Corti at 1-year post-drug treatment. Apical and basal turns from the same ear are shown in panels $\mathbf{A}$ and $\mathbf{B}$ and $\mathbf{C}$ and $\mathbf{D}$, respectively. Inner and outer HCs are missing, yet the tunnel of Corti $(T)$ remains intact. Intracellular filament bundles are prominent in Deiters' $(D)$ (arrows) and pillar cell $(P)$ cytoplasm. Low magnifications of the spiral ganglion cell region $(S G)$ in these sections are included in the insets of $\mathbf{A}$ and $\mathbf{B}$, and higher magnifications are shown in $\mathbf{B}$ and $\mathbf{D}$. For comparison, a low

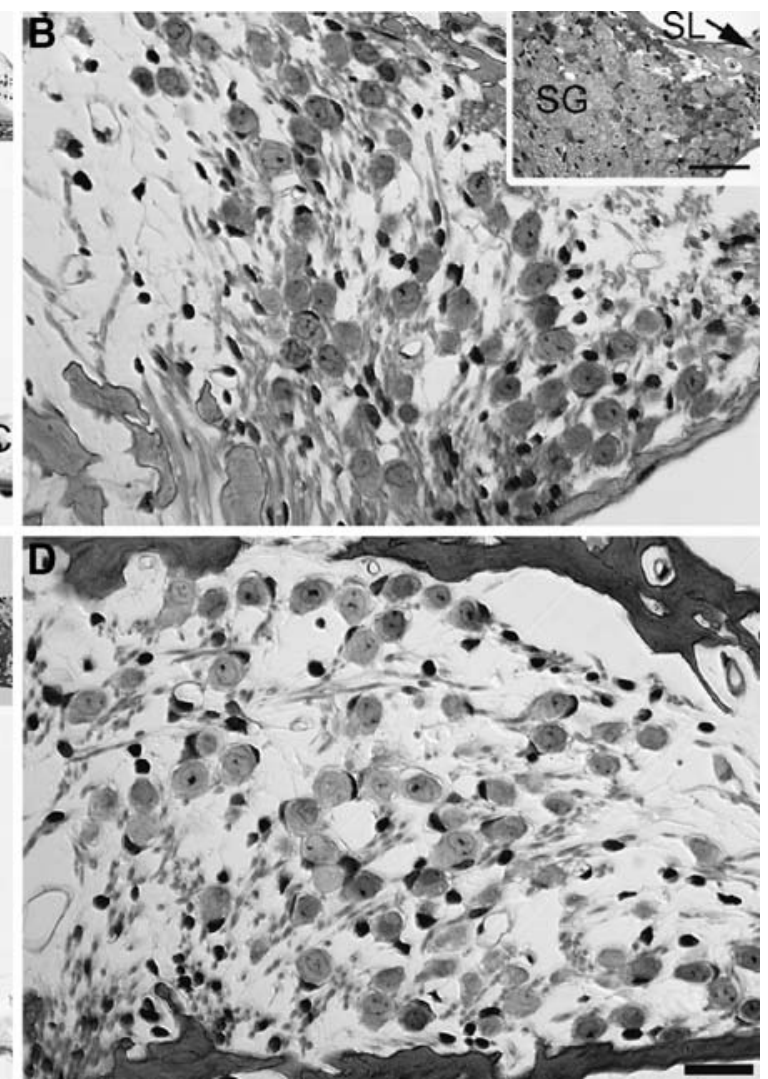

magnification micrograph of the spiral ganglion region from a normal control animal is included in the inset of panel $\mathbf{B}$. Fewer spiral ganglion cells are present in experimental than control animals. Darkly stained Schwann cell nuclei are seen throughout the spiral ganglion of experimental animals, especially in close proximity to the remaining ganglion cell bodies. Myelinated nerve fibers are scattered among the ovoid-shaped ganglion cell bodies. Scale bar is identical for panels A-D and equals $20 \mu \mathrm{m}$. Scale bars for the insets equal $50 \mu \mathrm{m}$. SL spiral limbus, $T M$ tectorial membrane, IS inner sulcus cells, $B$ border cells, $C$ Claudius cells. 


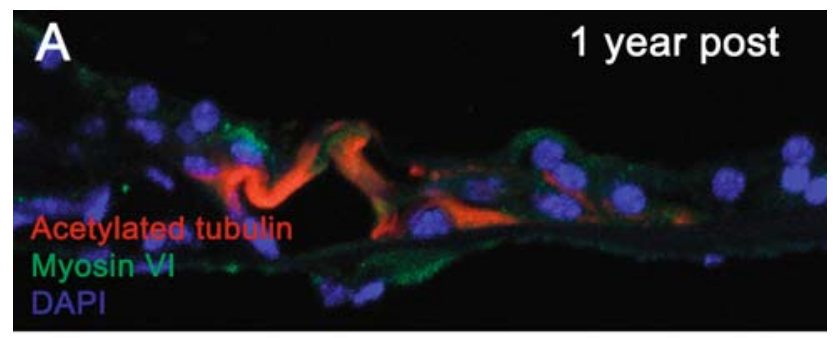

\section{B}

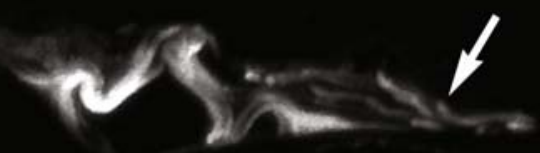

Acetylated tubulin
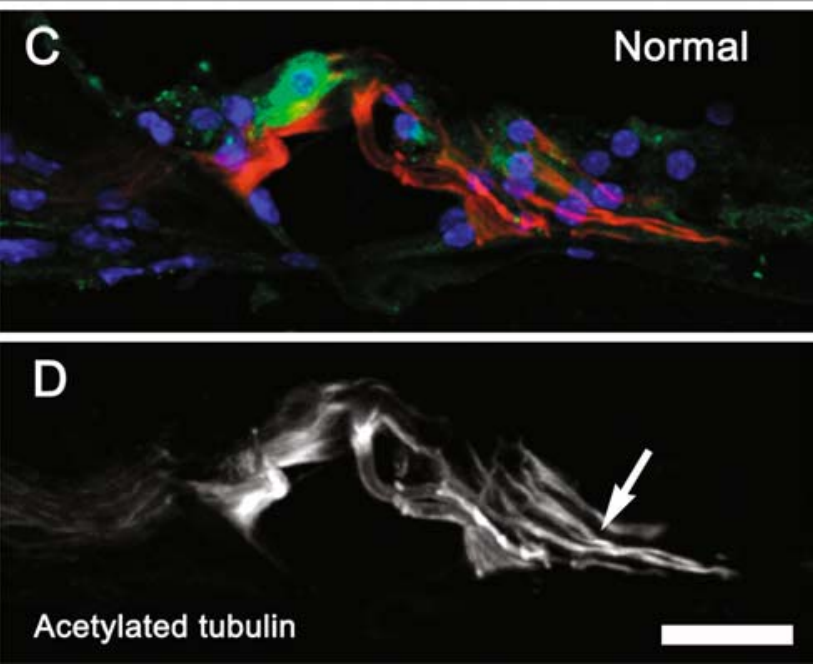

FIG. 3. Acetylated-tubulin labeling is retained in pillar and Deiters' cells 1 year after insult. Confocal images of cryostat sections taken from a drug-damaged mouse (A and $\mathbf{B}$ ) and an undamaged control mouse ( $\mathbf{C}$ and $\mathbf{D})$ labeled for acetylated tubulin (red) and myosin VI (green). Nuclei are counterstained for DAPI (blue). All channels are shown in $\mathbf{A}$ and $\mathbf{C}$. The acetylated-tubulin channel alone is shown in B and D. A and B Apical turn organ of Corti from a kanamycin/ furosemide-damaged mouse killed 1 year after the drug injection. $\mathrm{OHCs}$ and IHCs are missing. Acetylated tubulin labels surviving inner and outer pillar cells and Deiters' cells (e.g., arrow). C and D Apical turn organ of Corti from a 1-year-old undamaged control mouse. Strong myosin VI label is seen in IHCs, weaker label is seen OHCs. Acetylated tubulin labels inner and outer pillar cells and Deiters' cells (arrow). Scale bar $=20 \mu \mathrm{m}$ and applies to all panels.

(Border, Inner phalangeal, Pillar, Deiters', and Hensen cells), even in regions totally devoid of HCs. The normal organized cytoarchitectural distribution and regularity of Sox2-labeled nuclei in the undamaged cochlea (Fig. $5 \mathrm{E}, \mathrm{F}$ ) is grossly disrupted in the drug-damaged animals, especially in the Hensen, Deiters', and pillar cell regions where the Sox2-labeled nuclei are no longer regularly arranged in discrete rows (Fig. 5C, D). The disruption can be seen in several dimensions; the radial/ longitudinal location and depth of nuclei in the epithelium can be altered.
Jagged1

Jagged1 (referred to as Serrate 1 in chick and SerrateA or Jagged1b in zebrafish) is a member of the Notch signaling pathway, a pathway known to play a pivotal role in the differentiation of HCs and SCs (reviewed in Kelley 2006a, b). Jagged1 is expressed in prosensory regions of the ear before cell differentiation and is required for the development of inner ear sensory organs (Adam et al. 1998; Morrison et al. 1999; Kiernan et al. 2006). Recently, it was shown to be expressed at low levels in a diffuse manner in SCs in the normal adult mammalian ear and maintained in aminoglycosidedamaged organ of Corti at 1, 2, 3, and 7 days of recovery (Oesterle et al. 2008). Jagged1 expression was examined in the kanamycin/furosemide-damaged ears 1 year after drug treatment. As shown in Figure 6, remaining organ
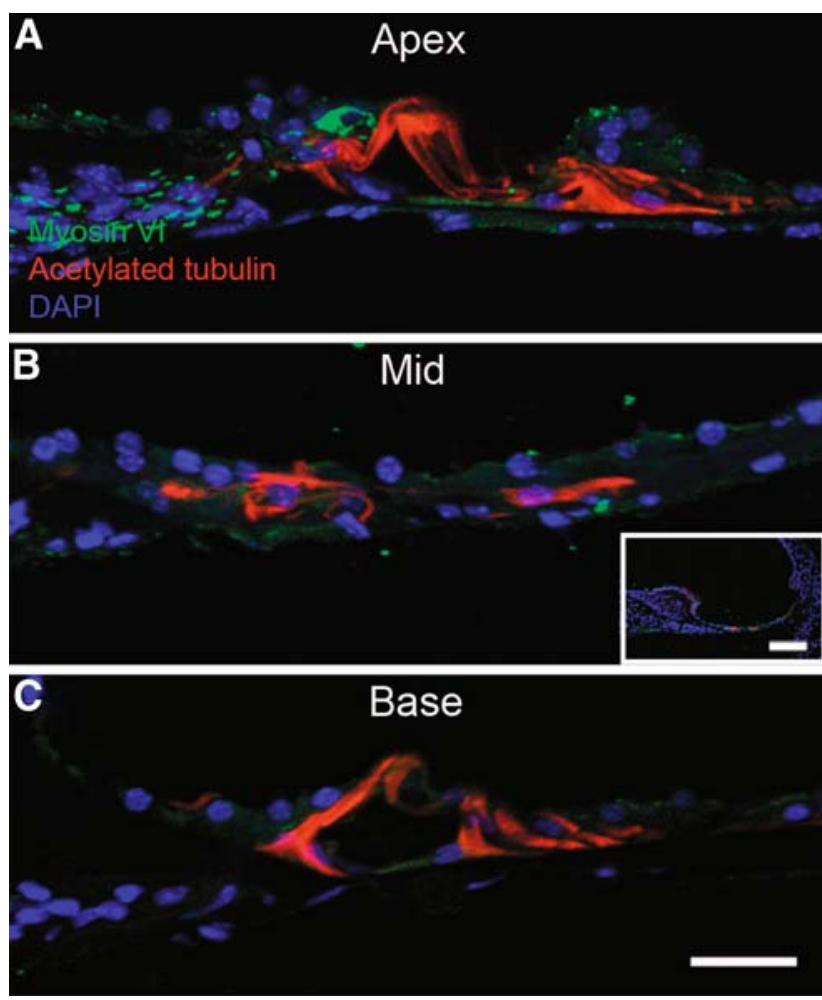

FIG. 4. Acetylated-tubulin labeling in the most severely drugdamaged animal examined. The epithelium thinned to approach a monolayer in the mid region of the cochlea in one of the eight drugdamaged animals studied. Shown are confocal images of cryostat sections taken from one ear of this animal that were labeled for acetylated tubulin (red) and myosin VI (green). Nuclei are counterstained for DAPI (b/ue). A Apex. A rare myosin VI-positive $\mathrm{IHC}$ is present and acetylated tubulin is expressed in pillar and Deiters' cells. The tunnel of Corti remains. B Mid region. All HCs are missing and the epithelium has thinned to approach a monolayer. Acetylated tubulin is still expressed in a subset of SCs. A low-magnification micrograph of this region is shown in the inset to illustrate the limbus is normal in shape, and the cut angle is appropriate. $\mathbf{C}$ Base. All HCs are missing, the tunnel of Corti is retained, and pillar and Deiters' cells express acetylated tubulin. Scale bar $=20 \mu \mathrm{m}$ and pertains to panels A-C. Scale bar for inset $=100 \mu \mathrm{m}$. 

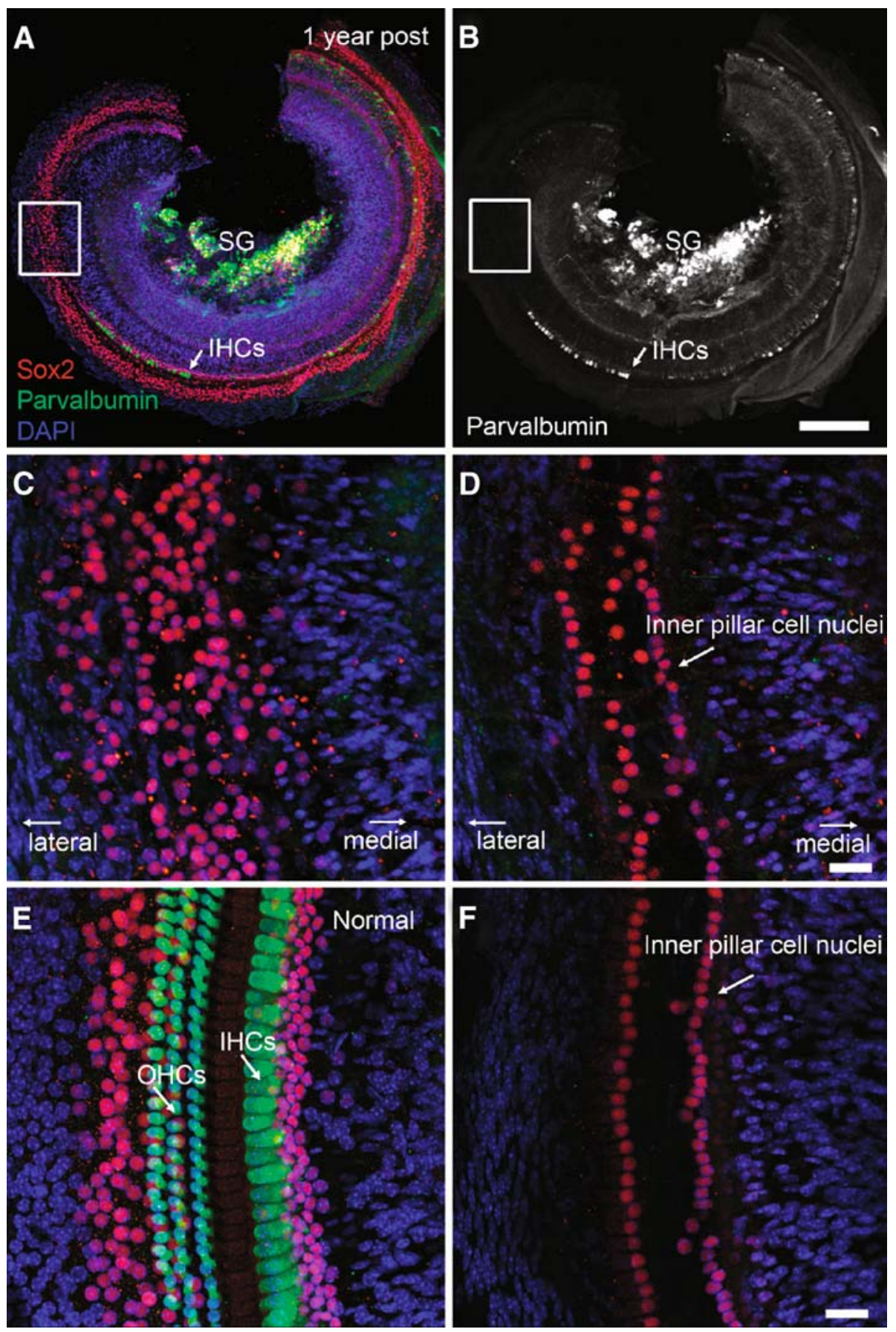

FIG. 5. Sox2 labeling is retained in SCs 1 year after insult. Confocal images of the apical turn of a kanamycin/furosemide damaged adult organ of Corti at 1 year of recovery (A-D) and an undamaged control animal (E and $\mathbf{F}$ ) immunolabeled with the transcription factor Sox2 (red) and parvalbumin (green). Nuclei are counterlabeled with DAPI (blue). Low-magnification images of the drug-damaged animal are shown in $\mathbf{A}$ and $\mathbf{B}$ and panel $\mathbf{B}$ shows just the parvalbumin channel. The boxed region in $\mathbf{A}$, a region devoid of HCs, is shown at higher

of Corti SCs continue to express Jagged1 in a diffuse manner in regions with a few scattered IHCs remaining, as well as in regions devoid of all HCs. SCs in all turns of the cochlea continue to express Jagged 1 and expression is observed in the most severely damaged animal in the

magnification in $\mathbf{C}$ and $\mathbf{D}$. The image in panel $\mathbf{C}$ is a brightest point projection of a confocal series spanning the sensory epithelium, whereas in $\mathbf{D}$ it is limited to the levels just above the floor of the tunnel to show the retention of the tunnel by the pillar cells. $\mathbf{E}$ and $\mathbf{F}$ Apical turn from a 1-year-old undamaged control mouse. Scale bar in B applies to panels A and B and equals 200 um. Scale bars in D and $\mathbf{F}$ equal $20 \mu \mathrm{m}$ and also apply to $\mathbf{C}$ and $\mathbf{E}$, respectively.

study, where the organ of Corti collapsed and thinned to approach a monolayer in the mid region of the cochlea (Fig. 6C).

In summary, marked changes in expression were not observed in drug-damaged versus control ears for 

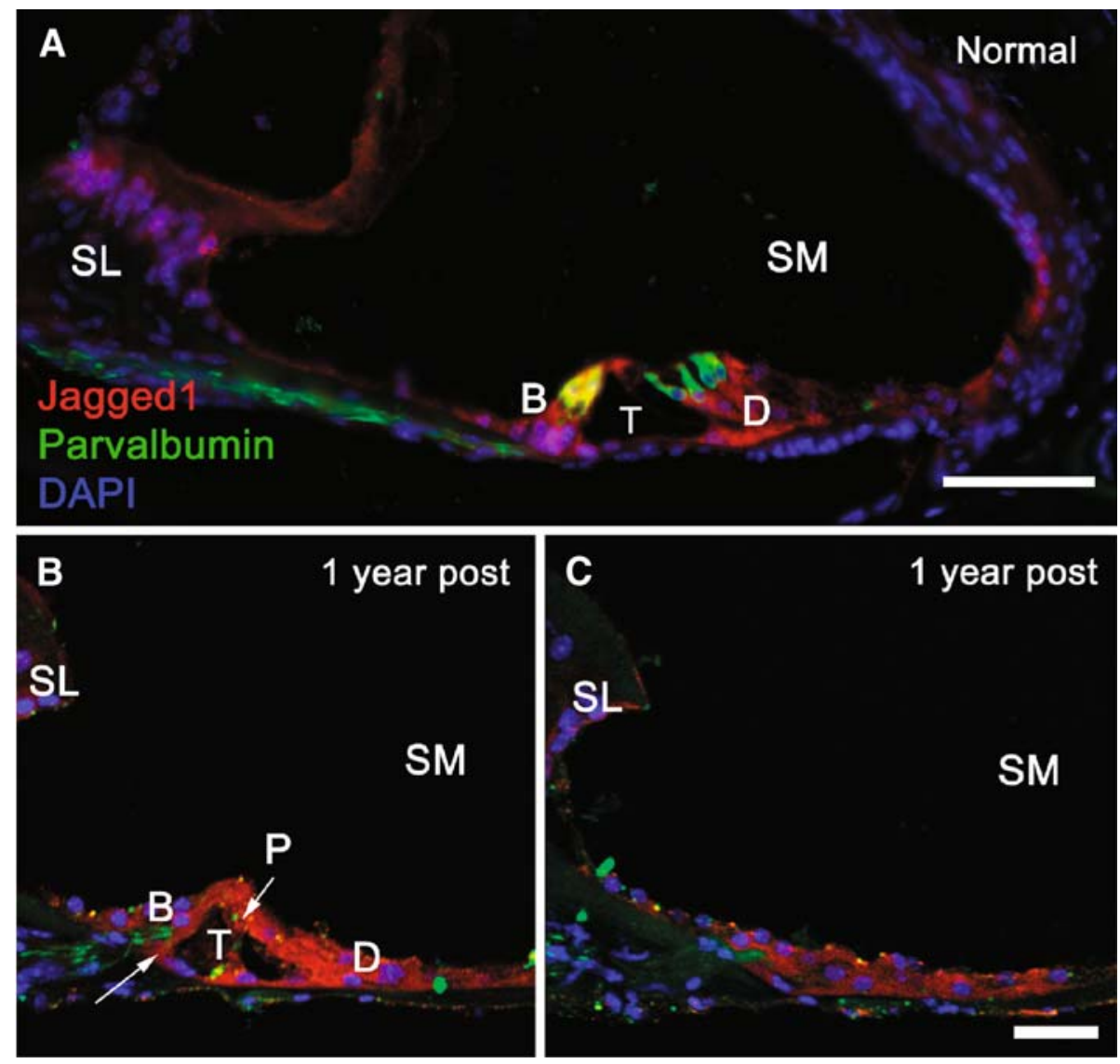

FIG. 6. Jagged 1 labeling in the organ of Corti 1 year after insult. Confocal images are shown of cryostat sections taken from normal (A) and kanamycin-furosemide damaged (B and $\mathbf{C}$ ) adult organ of Corti immunolabeled with Jagged1 (red) and parvalbumin (green). Nuclei are counterlabeled with DAPI (blue). A 5-month-old undamaged control mouse. B and $\mathbf{C}$ Sections are shown from the middle turn of two drug-injected animals sacrificed 1 year after the

all three proteins studied, suggesting an absence of marked SC dedifferentiation 1 year after drug insult.

\section{SPIRAL GANGLION CELL DENSITY IS REDUCED}

Light microscopic examination of the ganglion cell region in plastic sections stained with toluidine blue demonstrated the marked loss of spiral ganglion neurons at 1 year of recovery relative to the undamaged controls. Panels B and D of Figure 2 show micrographs of sections through the ganglion region where the cell bodies of remaining spiral ganglion cells are sparse. Spiral ganglion cell density is decreased visà-vis controls (e.g., inset in panel B), and large clear spaces are apparent in experimental animals that are not seen in controls. These trends were further confirmed during observations of neurofilamentlabeled or parvalbumin-labeled ganglion cells in cryostat sections from drug-damaged and normal control

kanamycin-furosemide injection. HCs are absent, but the tunnel of Corti $(T)$ is retained in one animal, the animal in B. Arrows point to pillar cells. A tunnel of Corti is not apparent in the animal shown in C. Jagged 1 is expressed in the remaining nonsensory cells in both drug-damaged animals. Scale bar in A equals $50 \mu \mathrm{m}$. Scale bar in $\mathbf{C}$ equals $25 \mu \mathrm{m}$ and applies to panels B and C. B Border cells, D Deiters' cells, $P$ pillar cell, $S L$ spiral limbus, $S M$ scala media.

animals (data not shown). Fewer neurofilament-positive or parvalbumin-positive ganglion cell bodies are seen in drug-treated animals than controls.

The changes in spiral ganglion cell density were quantitatively assessed at 1-year post injection and at a short recovery time, 30-days post injection. Plastic sections from one ear of each animal were viewed on compound microscope, and digital images were collected of the spiral ganglion region in the cochlear apex and base. Spiral ganglion cell density was quantified for both regions. A $12 \%$ and $29 \%$ decrease in spiral ganglion density is seen in the apical and basal turns, respectively, in 30-day post injection animals relative to undamaged controls (Fig. 7). Statistical analysis with a two-way ANOVA and Bonferroni post-test yielded significant $p$ values for the base $(p<0.001)$. Larger decreases in spiral ganglion cell density are seen at 1-year post injection relative to the undamaged controls (apex: $58 \%$ decrease, $p<0.001$; base: $55 \%$ decrease, $p<0.001)$. Spiral ganglion cell density decreased significantly in the 1-year post injec- 


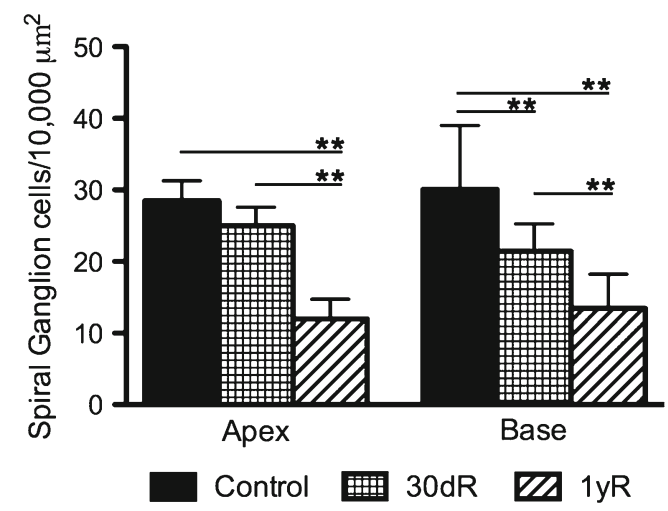

FIG. 7. Spiral ganglion cell density is decreased after drug insult. Mean $( \pm S D)$ density of spiral ganglion cells at different cochlear locations in undamaged and kanamycin/furosemide-damaged animals at 30 days $(30 d R)$ and 1 year of recovery $(1 \mathrm{yR})$. Double asterisks indicates significance at the 0.001 level.

tion animals relative to the 30-day post injection animals in both the apex and base (apex: $p<0.001$; base: $p<$ $0.001)$. These results indicate that the kanamycin/ furosemide protocol was effective in producing a significant decrease in the population of spiral ganglion cell neurons at 30 days post injection and that this difference increased further by 1 year. Forty-two percent to $45 \%$ of the spiral ganglion neurons remain 1 year after the kanamycin/furosemide injection.

\section{Peripheral neural processes are reduced 1 year} after treatment and abnormal innervation patterns are present

Peripheral neural processes to the organ of Corti were examined in whole-mount preparations immunolabeled for neurofilament or parvalbumin. Both neurofilament and parvalbumin labeling are prominent in the most peripheral region of the peripheral processes, where the processes become unmyelinated before projecting toward the organ of Corti. The myelinated regions of the peripheral processes that lie within the osseous spiral lamina are lightly labeled (Fig. 8F, G) or unlabeled, possibly a consequence of antibody penetration problems within this region or the fibers being myelinated here. In the normal cochlea the peripheral processes of type I afferents form synaptic contacts on IHCs in close proximity to the habenula perforata opening from which they emerge and neural processes that cross the tunnel (tunnel efferents and type II afferents) do so in a characteristic uniform manner. Neural innervation to the organ of Corti is markedly decreased in the experimental animals relative to controls 1 year after the drug treatment, and abnormal innervation patterns are seen (Figs. 8, 9, and 10). Peripheral processes crossing the tunnel of Corti are dramatically reduced in experimental animals relative to controls, with only rare fibers crossing the tunnel to
FIG. 8. Neural innervation to the organ of Corti is markedly reduced 1 year after insult. Confocal images are shown of the apical turn of a kanamycin/furosemide-damaged animal at 1 year of recovery $(\mathbf{A}-\mathbf{E})$ and an undamaged control cochlea $(\mathbf{F}$ and $\mathbf{G})$ that are immunolabeled for Sox 2 (red), myosin VI (green), and neurofilament (b/ue). Brightest point projections from confocal Z series spanning the sensory epithelium are shown. A A low-magnification image of the drug-damaged animal. Only the channel with the $\mathrm{HC}$ marker, myosin $\mathrm{VI}$, is shown to illustrate numbers and patterns of remaining HCs. The arrowhead points to the extreme apex, and a stretch of tissue is folded over on itself here. Virtually all OHCs are gone. Several clusters of IHCs remain, and spotty scattered IHCs are seen in some regions. Stretches of tissue exist with no remaining HCs. The region in the lower box is shown at higher magnification in panels $\mathbf{B}$ and $\mathbf{C}$. The upper-boxed region is shown in $\mathbf{D}$ and $\mathbf{E}$. B Sox2 (red) labels organ of Corti SCs and assists in delineating sensory epithelial boundaries. Two myosin VI-labeled IHCs (green) remain in this region. Neurofilament-labeled nerve fibers (blue) are present in the region devoid of HCs. For clarity, the neurofilament labeling alone is shown in panel $\mathbf{C}$. Note the neural tangle (arrow) a distance from the two remaining IHCs. Tunnel crossing peripheral processes are nearly absent. $\mathbf{D}$ and $\mathbf{E}$ Higher magnification of the region in the upper box in panel A. All OHCs are missing and one myosin VIlabeled IHC remains (arrow). The neurofilament labeling only is shown in E. Note the neurofilament-labeled fibers in regions devoid of HCs (e.g., asterisks). Peripheral neural processes in the drugdamaged animal are markedly reduced relative to undamaged control animals ( $\mathbf{F}$ and $\mathbf{G}$ ). $\mathbf{F}$ and $\mathbf{G}$ Apical turn from a 1-year-old undamaged mouse. Just the neurofilament labeling is shown in G. Peripheral processes exit individual habenula perforata and project towards the base of the IHCs. Efferent peripheral processes project laterally along the inner spiral bundle (open arrowhead) or cross the tunnel of Corti (open arrow). Smaller type II afferent fibers also cross the tunnel of Corti (arrow). OSL osseous spiral lamina. Scale bar equals $200 \mu \mathrm{m}$ in A. Scale bar in C applies to panels $\mathbf{B}$ and $\mathbf{C}$ and equals $20 \mu \mathrm{m}$, scale bar in $\mathbf{G}$ applies to $\mathbf{D}-\mathbf{G}$ and equals $20 \mu \mathrm{m}$.

wander in the region formerly occupied by OHCs (e.g., Fig. 9B). This indicates a severe disruption to the type II afferents and tunnel crossing efferent fibers in the experimental animals. In regions with sporatic IHCs remaining, fibers frequently degenerate back to the vicinity of the habenula perforata and persist, despite the absence of HCs in the immediate vicinity (Figs. 8B$\mathrm{E}$ and $9 \mathrm{C}, \mathrm{D})$. There is a substantial reduction of fibers in the habenula perforata, indicating that type I afferents, the most numerous neuron type within the habenula, are impacted by the absence of IHCs.

Spontaneous "resprouting" of spiral ganglion neuron processes has been reported in a number of species (chinchillas, guinea pigs, and cats) after different forms of cochlea damage, including aminoglycoside ototoxicity (reviewed in Pettingill et al. 2007). Abnormal innervation patterns consistent with resprouting are present in regions with marked IHC loss. The resprouting processes were identified morphologically on the basis of their abnormal projection patterns that are substantially different from the well-structured and uniform innervation patterns characteristic of the normal undamaged cochlea. In the kanamycin/furosemide-injected animals, peripheral processes are seen that reverse direction by looping back onto themselves. Abnormal 

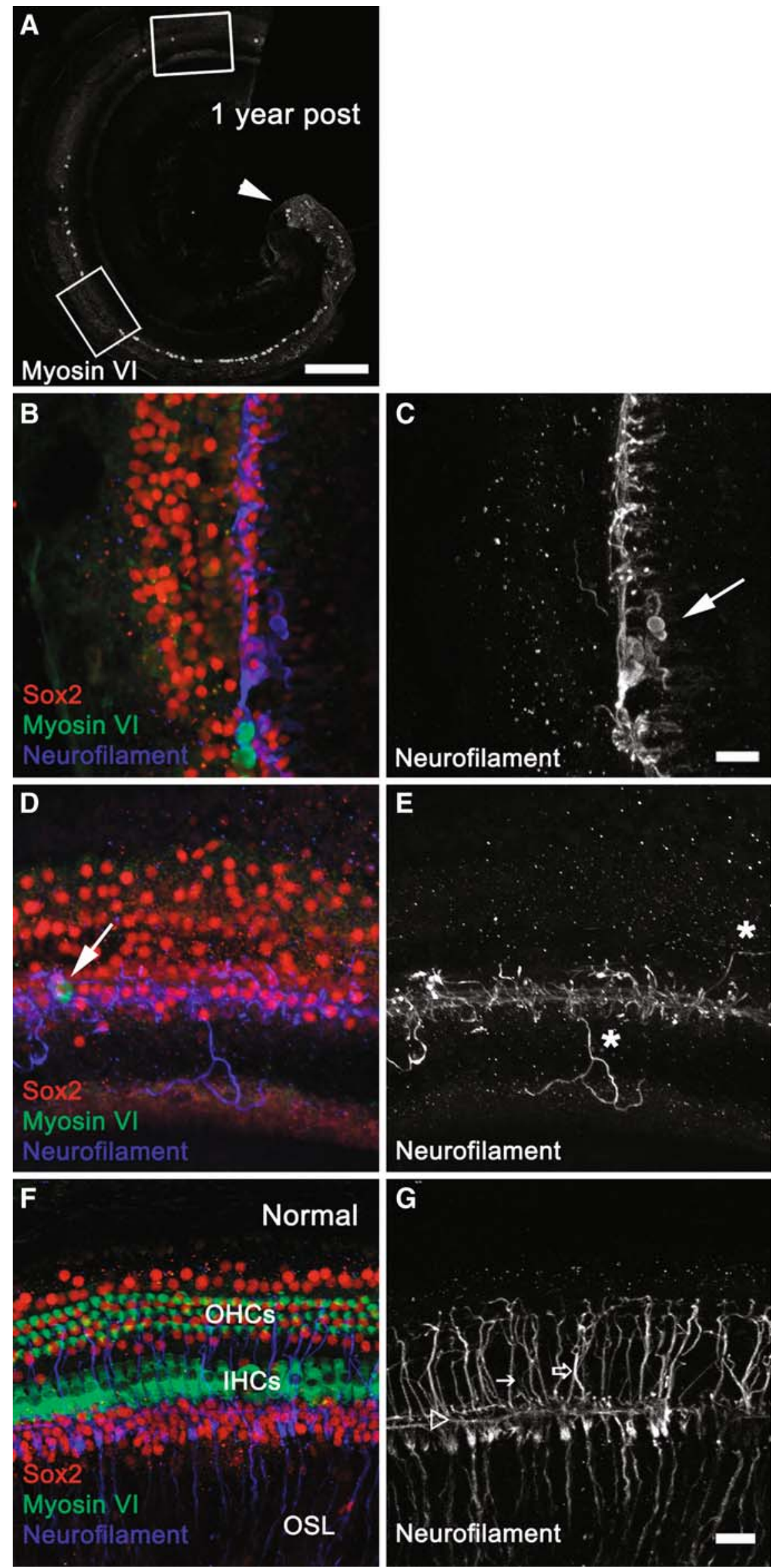

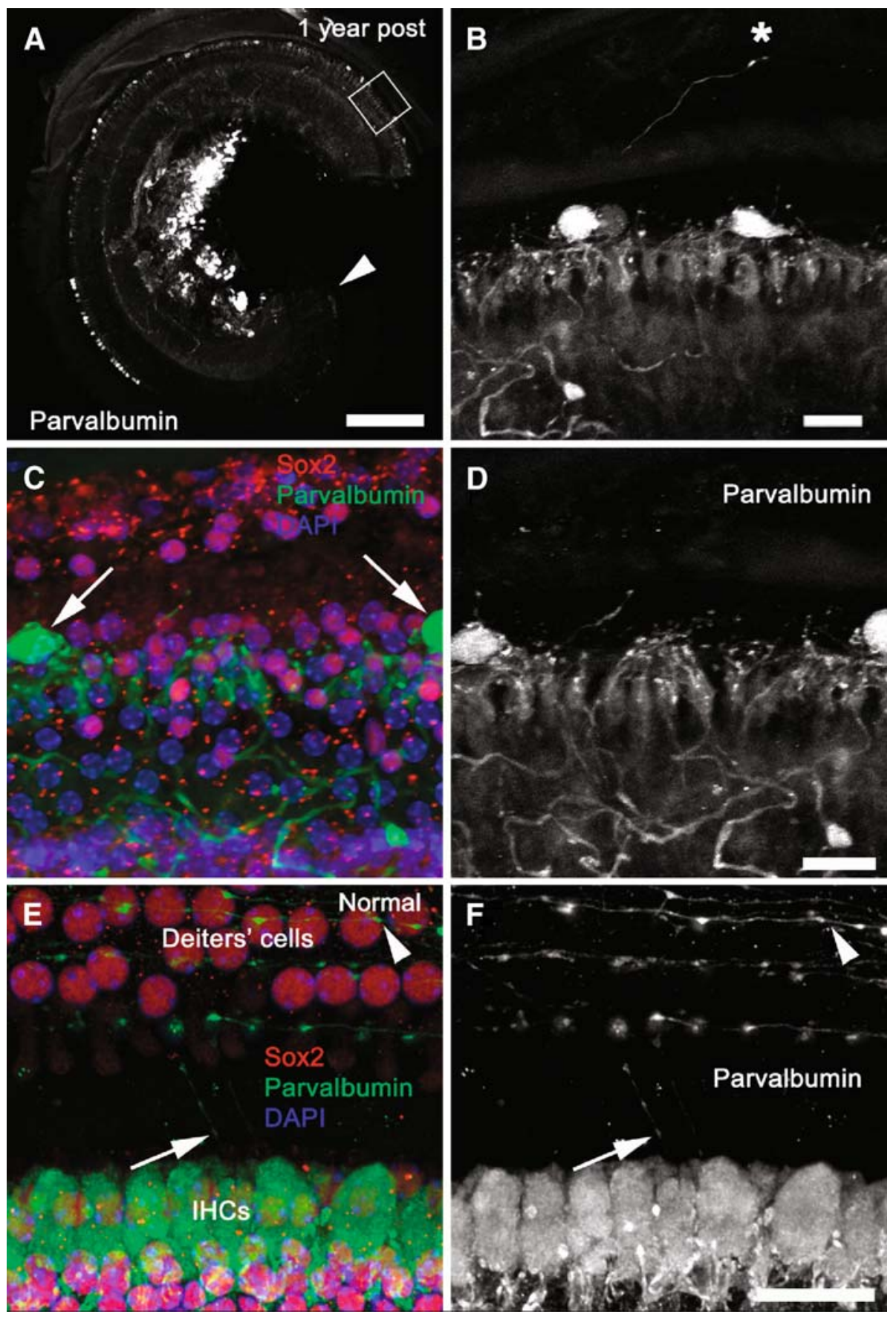

FIG. 9. Abnormal nerve fiber branching in drug-damaged animals 1 year after insult. Confocal images are shown of the apical turn of a kanamycin/furosemide-injected animal at 1 year of recovery $(\mathbf{A}-\mathbf{D})$ and an undamaged, 1-year-old, control animal (E and $\mathbf{F})$ that are double-labeled for Sox2 (red) and parvalbumin (green) and counterstained with DAPI (blue). Brightest point projections from confocal Z series spanning the IHC region are shown in B-F. A A lowmagnification image of parvalbumin-labeled HCs in the apex 1 year after insult. The region in the box is shown at a higher magnification in panels $\mathbf{C}$ and $\mathbf{D}$, and the region abutting the right side of the box is shown in B. B Just the parvalbumin channel is shown to illustrate a nerve fiber (asterisk) that extends into a region devoid of $\mathrm{HCs}$, a region formerly occupied by $\mathrm{OHCs}$, and abnormal neural branching medial to the IHCs. The abnormal branching is shown at a higher magnification in panels $\mathbf{C}$ and $\mathbf{D}$. C and $\mathbf{D}$ Two parvalbumin-labeled
IHCs remain (arrows). Just the parvalbumin channel is shown in $\mathbf{D}$ Note the degeneration of fibers back to the vicinity of the habenula perforata in the area totally devoid of HCs, the extensive branching medial to the habenula perforata, and the disordered innervation pattern. E Apical turn from a normal undamaged animal 1 year in age. IHCs (green) are visible. OHCs are present in the more lumenal region of the tissue that is not included in the brightest point projection, because it would have obscured the nerve fibers under the OHCs (arrowhead). F Parvalbumin channel alone. Note the longitudinally oriented nerve fibers in the Deiters' cell region (arrowhead) that are not apparent in the drug-damage animal (see B, D) and the thin tunnel crossing fiber (arrow). Scale bar equals $200 \mu \mathrm{m}$ in $\mathbf{A}$. Scale bars in $\mathbf{B}, \mathbf{D}$, and $\mathbf{F}$ equal $20 \mu \mathrm{m}$. Scale bars in $\mathbf{D}$ and $\mathbf{F}$ apply to $\mathbf{C}$ and $\mathbf{E}$, respectively. 

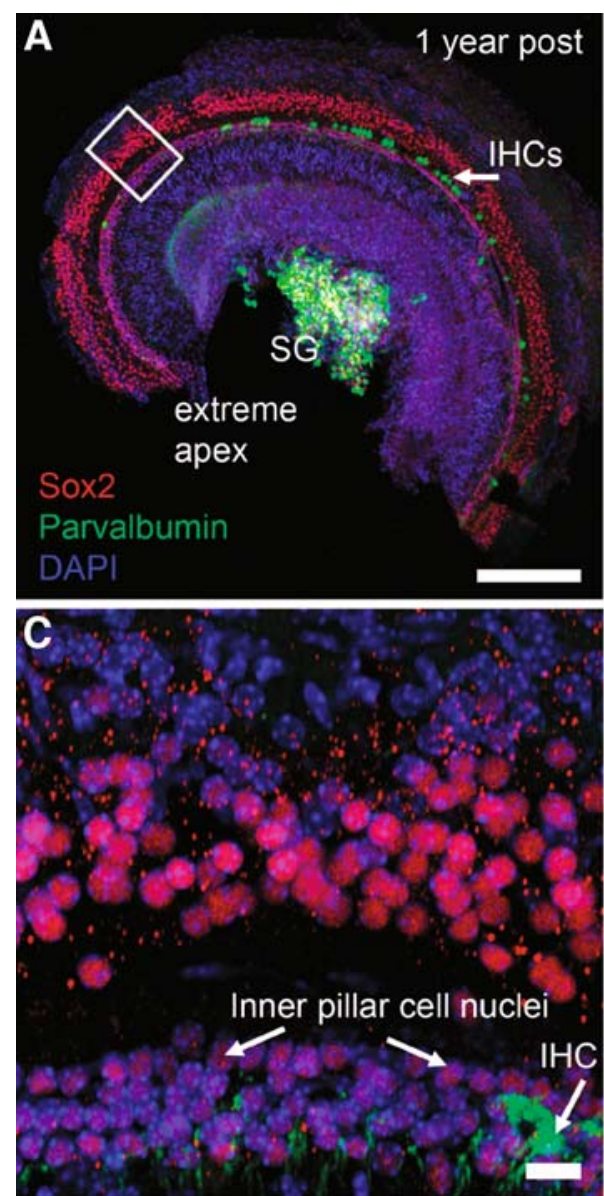

FIG. 10. Neural growth cones in the damaged organ 1-year posttreatment. Confocal images of an apical turn whole-mount preparation from a drug-damaged animal 1-year post-treatment that was immunolabeled for Sox2 and parvalbumin and counterstained with DAPI. A and B Low-magnification images of the turn are shown. Panel B shows the parvalbumin channel alone. The boxed region is shown at higher magnification in panels $\mathbf{C}$ and $\mathbf{D}$. C and $\mathbf{D}$ Brightest point projections from a confocal Z series spanning the sensory

branching patterns are seen where processes branch medial to the habenula perforata and IHC region and course their way laterally, sometimes in a jumbled tangle of processes (Figs. 8D, E and 9B-D). Branching can also be seen in, or lateral to, the tunnel of Corti where one branch travels longitudinally towards the apex and the other meanders longitudinally towards the base (data not shown). Abnormal neural tangles (Fig. 8B, C) and growth cones (Fig. 10) are also present in the organ of Corti remnants. Thick and thin diameter fibers are present within the drug-damaged organ of Corti.

Stria vascularis thickness is decreased after drug treatment

Measurements of strial thickness (from the endolymphatic surface of the marginal cells to the spiral ligament side of the basal cells) were obtained from images taken of cross-sections of plastic-embedded cochleas collected
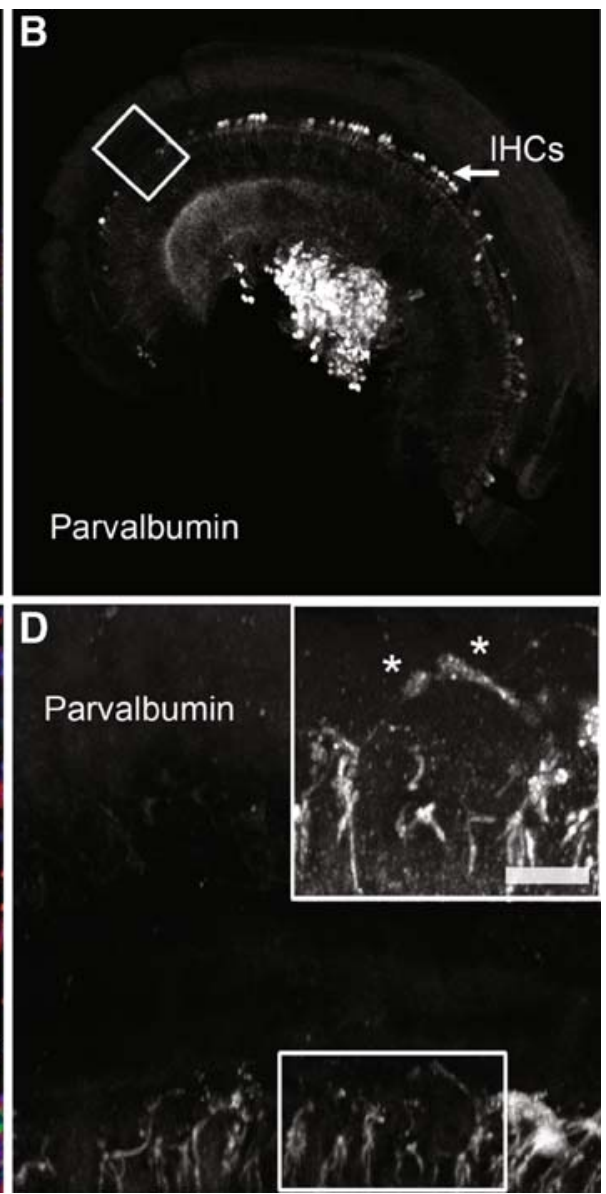

epithelium. The parvalbumin channel is shown alone in panel D. A single abnormally shaped IHC remains (arrow), all other HCs are missing. Many Sox2-positive SCs remain. Parvalbumin-labeled nerve fibers that have degenerated back to the region of the habenula perforata remain in regions without HCs. The boxed region is shown at higher magnification in the inset. Two growth cones (asterisks) are present in close proximity to the remaining IHC. Scale bar $=200 \mu \mathrm{m}$ for panel A, $20 \mu \mathrm{m}$ for panel C, $10 \mu \mathrm{m}$ for inset in panel $\mathbf{D}$.

from drug-injected animals at 30 and 80 days and 1-year post kanamycin/furosemide treatment. Measurements were collected from the apical and basal turns of each cochlea. Mean values ( \pm the $\mathrm{SD}$ ) and ranges are given in Table 2. Analogous measurements were also taken from control animals. ANOVA statistics revealed a significant decrease in strial thickness for both the apical and basal turns of the drug-injected animals at all recovery times examined relative to the undamaged controls. Strial thickness is decreased significantly vis-à-vis controls by the first post treatment time point studied, 30-days post insult, and did not progress further with additional post treatment time.

\section{DISCUSSION}

Previously, we characterized the kanamycin-furosemide protocol used here to induce HC loss in adult 
TABLE 2

\begin{tabular}{lcr}
\hline & TABLE 2 & \\
\hline & Stria vascularis thickness $(\mu \mathrm{m})$ & Base $($ range) \\
\hline Controls (no insult) & Apex (range) & $13.7 \pm 0.4(13.1-14.0)$ \\
30 days post-insult & $14.3 \pm 0.7(13.5-15.8)$ & $8.7^{\mathrm{a}} \pm 0.4(6.1-12.0)$ \\
80 days post insult & $10.7^{\mathrm{a}} \pm 0.7(6.7-13.1)$ & $11.4^{\mathrm{a}} \pm 0.3(9.4-12.6)$ \\
1-year post insult & $9.4^{\mathrm{a}} \pm 0.6(8.4-10.5)$ & $10.8^{\mathrm{a}} \pm 0.3(7.6-14.1)$ \\
\hline
\end{tabular}

Mean values \pm SD followed by the range

${ }^{a}$ Significance from control at the $<0.001$ level

mice at recovery time points out to 3 months, with cursory information collected at 1 year (Oesterle et al. 2008). Because little is known regarding the molecular characteristics of long, badly damaged mammalian auditory epithelium, we expanded our previous work by carefully characterizing the organ at 1-year post treatment. This information is critical for developing therapeutic strategies to repair the epithelium. Having this information delineated in mice is particularly important in light of the unparalleled capacity for genetic manipulation in these animals. This study demonstrates the following: (1) substantial IHC loss, virtually total OHC loss, and some SC loss occurs at 1 year; (2) the cytoarchitectural arrangement of the organ of Corti is disturbed 1 year after insult, but pillar cells and the tunnel of Corti are typically retained; (3) marked SC dedifferentiation is not seen, as evidenced by retention of acetylated tubulin, Sox2, and Jagged1 labeling in SCs 1 year after treatment; (4) spiral ganglion cell density is decreased 30-days post injection and decreases further by 1 year; (5) some peripheral nerve fiber processes survive 1 year after extensive HC loss, many degenerate back to the vicinity of the habenula perforata; and (6) strial thickness is significantly decreased 1 year after insult.

\section{Increased IHC loss with time}

First developed in the 1970s, the combination of a single dose of aminoglycoside closely followed by a single dose of a loop diuretic is known to cause rapid HC loss in humans and experimental animals (West et al. 1973; Russell et al. 1979; Brummett et al. 1981; Webster and Webster 1981). For unknown reasons, lesioning the adult mouse cochlea proved to be considerably more difficult than lesioning other rodents such as guinea pig or chinchilla (Wu et al. 2001). Just recently an aminoglycoside/loop diuretic combination to kill cochlear HCs in the mouse was developed (Taylor et al. 2008; Oesterle et al. 2008). A kanamyin-furosemide protocol used in adult mice rapidly generates widespread OHC loss. Virtually all OHCs are lost 3 days following the drug insult (Oesterle et al. 2008). The lesion pattern and time course is not specific to the loop diuretic used, for it is similar to patterns seen with bumetanide and kanamycin (Taylor et al. 2008).

Previously, we noted a delayed IHC loss relative to the rapid $\mathrm{OHC}$ loss and the persistence of large numbers of apical IHCs at 11 weeks of recovery. Marked IHC loss was seen in only a small subset of the animals $(<5 \%)$ at 11 weeks. Greater IHC death (in $50 \%$ of all cochleas examined) is reported in kanamycin-bumetanide-damaged animals at 3 months (Taylor et al. 2008), and this difference may be attributable to the different strains used and/or different ages at time of drug injection. TUNELpositive HC nuclei, activated caspase 3 labeling, and morphology consistent with apoptosis suggest that apoptosis is the mode of HC death for the aminoglycoside/loop diuretic-induced lesions (Taylor et al. 2008). The mechanisms underlying the initial IHC survival compared to the OHCs are unknown. As shown in the present study, continued IHC loss occurs with increased recovery time. The mechanisms contributing to the slow IHC degeneration remain to be determined. It is conceivable that changes in the stria vascularis and composition of the scala media play a role. Marked strial abnormalities, including changes in strial thickness and marginal cell degeneration, were reported following a kanamycin-bumetanide lesion (Taylor et al. 2008), and significant strial thinning was seen in the present study.

It cannot be ruled out that the persistence of the tunnel of Corti and lack of SC dedifferentiation 1 year after drug treatment in regions totally devoid of HCs may be attributable to recent IHC death. Because of an absence of recovery time points between 3 months and 1 year, a detailed time course of the additional IHC loss seen in this study cannot be delineated. Marked IHC loss (in addition to the OHC loss) was observed in an animal killed at 10 months of recovery. With ototoxic lesions, IHC loss typically occurs several days to several months following OHC loss (e.g., Ladrech et al. 2007). However, prolonged IHC survival after extensive OHC loss has been observed in mice with specific genetic alterations that lead to $\mathrm{HC}$ death. In mice lacking the Kcc4 cotransporter, 
IHCs can survive for several months (Boettger et al. 2002), and IHCs can be present at 6 months in Barhll-deficient mice while the OHCs are completely lost by postnatal day 59 (Li et al. 2002).

\section{Absence of transition to a monolayer}

Mice are more resistance to ototoxic damage than other mammals such as guinea pigs, rats, and chinchillas, and very high doses of aminoglycoside need to be administered to mice before any ototoxicity is evident (Wu et al. 2001). It is important to note that the concentrations of aminoglycoside and loop diuretic used in this study are several times higher than those used for guinea pigs and rats (e.g., Leonova and Raphael 1997; Li et al. 1999), and that the damage observed in these other species progresses and is more severe (degrades to a monolayer) than that seen here. The increased resistance of mice to aminoglycoside-induced damage is not a kanamycin-specific phenomenon, as it has also been observed when either amikacin or gentamicin is administered instead of kanamycin (Taylor et al. 2008). The reasons for the increased resistance are not known, but may be attributable to heightened resistance of the IHCs in particular (Taylor et al. 2008). The increased sensitivity of other rodents to ototoxic damage and the rapid progression of the damage to a flattened epithelium in these species raise questions as to possible direct effects of the drugs on the SCs in addition to the sensory cells in these animals.

In rodents, the transition from a normal organ of Corti to a flat epithelium can proceed rapidly, within 1 to 2 days (guinea pig: Kim and Raphael 2007), within 10 weeks (rat: Ladrech et al. 2007), or within several months (McFadden et al. 2004) of an aminoglycoside insult. Hence, the persistence of the tunnel of Corti and maintained morphological differentiation of the SCs 1 year after drug treatment that were seen here in spite of marked HC loss and partial SC loss is unusual, but it is not unprecedented. For example, differentiated SCs can persist for 3-years post treatment in cats after a series of kanamycin injections in spite of total HC loss (Sugawara et al. 2005). In one of the eight animals studied (Figs. 4B and 6C), a flattening of the sensory epithelium was observed in the mid region, but not in the base. This monolayer-like appearance was observed in multiple sections taken from this animal and did not appear to be the result of a poor cut angle as evidenced by a normal limbus shape. The presence of this pattern in multiple sections with good cut angle suggests the monolayerlike appearance is not an artifact of cryosectioning. Aminoglycoside lesions to the auditory epithelia can start in the mid region prior to spreading basally and apically with additional time (McFadden et al. 2004).
The reason for the higher vulnerability of the middle turn remains to be determined. It is possible that with additional post kanamycin/furosemide treatment time further degeneration to a monolayer would occur in the more basal regions as well. It is also possible that use of a higher kanamycin concentration could lead to expanded regions with monolayer morphology.

\section{Absence of marked SC dedifferentation}

The expression of three known SC markers was examined to investigate for possible SC dedifferentiation after damage. Acetylated tubulin, Sox2, and Jagged1 persist in SCs in the damaged ear 1 year after insult. This, and the lack of morphological evidence for dedifferentiation (i.e., maintenance of distinctive pillar cell morphology and continued presence of phalloidin and acetylated tubulin-labeled intracellular filament bundles within the pillar and Deiters' cells), suggests a lack of marked SC dedifferentiation after damage. Further support for this idea comes from the recent finding in mice that the gap junctional connexins Cx26 and Cx30 and the K-Cl cotransporter isoform KCC4 persist in SCs 14 weeks after kanamycin-bumetanide damage (Ruth Taylor and Andy Forge, personal communication). While the expression of the three SC markers in the damaged animals suggests an absence of marked dedifferentiation, observed shape changes in Deiters' cells, i.e. their rounding up (Taylor et al. 2008), are consistent with some dedifferentiation occurring in these cells. Clearly, additional studies are needed to further examine for possible SC cellular dedifferentiation; however, we are limited by the paucity of identified SC-specific markers at present. One potentially promising area will be the exploration of the inwardly rectifying potassium channels (Kir), as a downregulation or inactivation of these channels has been proposed to represent a hallmark of glial cellular dedifferentiation, and to be a precondition for Müller cell proliferation (Bringmann et al. 2000).

The maintenance of the SC markers in the damaged mouse epithelium, including the animal where the epithelium approached a monolayer, suggests that cells remaining in the flat epithelium could be SCs such as Deiters' or pillar cells that have undergone marked morphological changes. Alternatively, the flat epithelium seen in other rodents (guinea pig, chinchilla) that occurs at shorter recovery times and is present in multiple turns of the cochlea may be the result of more marked SC dedifferentiation and loss than that seen in mouse. It is possible that some SC markers studied here may not be expressed with a more severe lesion. Future studies in guinea pig and chinchilla are needed to 
explore this. The flat epithelium in the guinea pig is known to be heterogeneous, apical tight junctions are maintained, and the cells can proliferate spontaneously (Kim and Raphael 2007). The nature of the cells that form the flat epithelium in the damaged cochlea remains uncertain, yet knowledge of the composition of the epithelium and how the cells interact will be of importance for gene transfer, cellular transformation, and stem cell therapies. Temporal bone studies of humans after aminoglycoside ototoxicity show a variety of morphologies, including residual SCs in the total absence of HCs or an undifferentiated monolayer (e.g., Matz et al. 1965). Hence, understanding the characteristics of non-sensory cells in both epithelial remnant types will be integral to the development of effective therapeutic strategies. Both types of epithelia may play a prominent role as the recipient of therapy.

\section{Neuronal survival}

The persistence of some peripheral processes in regions of total HC loss, the sprouting of nerve fibers, and retention of spiral ganglion cell bodies seen with our mouse model in the present study are harmonious with findings reported from other mammals. Looking at the latter, marked HC loss in the organ of Corti resultant from acoustic trauma or ototoxic antibiotics has long been thought to result in secondary degeneration of spiral ganglion cells. Degeneration of the peripheral axons of the spiral ganglion cells is detectable within days of the initial insult, and ganglion cell body degeneration can occur within weeks of the insult (Johnsson 1974; Liberman and Kiang 1978), but some ganglion cells can survive for months or years after severe HC loss (Spoendlin 1975; Webster and Webster 1981, 1982; Koitchev et al. 1982; Dodson et al. 1994). We observed increased spiral ganglion cell loss in drug-damaged mice 1-year post injection, relative to 30 -days post injection, and retention of $42-45 \%$ of the spiral ganglion cells at 1 year. Studies of human temporal bones have also shown that ganglion cells frequently survive in badly damaged ears (Kerr and Schuknecht 1968; Nadol et al. 1989), even in ears with total HC loss (Teufert et al. 2006).

Spiral ganglion cell peripheral processes can persist in badly damaged ears and wander within regions with total HC loss (Wright 1976; Bohne and Harding 1992). Spiral ganglion neurons are not replaced once they have degenerated, but surviving spiral ganglion neurons are able to resprout and regrow their peripheral processes in vivo following deafferentation. The spontaneous regrowth or sprouting of nerve fibers in response to severe trauma to the organ of Corti has been described after various types of inner ear trauma in a variety of mammals (Johnsson and Hawkins 1972; Spoendlin and Suter 1976; Wright 1976; Terayama et al. 1977, 1979; Webster and Webster 1982; Bohne and Harding 1992; Lawner et al. 1997). The resprouting processes were identified morphologically on the basis of their abnormal projections that are substantially different to the well-structured and uniform innervation patterns seen in the normal undamaged cochlea. Acetylcholinesterase immunohistochemistry (AChE) in noise-damaged chinchilla cochlea has shown that the regenerated fibers do not express AChE, suggesting they are not efferent and therefore most likely are afferent (Strominger et al. 1995). The spiral ganglion cell and peripheral process survival may be dependent on trophic support provided by SCs remaining in the epithelium and erbB receptor signaling (Stankovic et al. 2004).

\section{Stria vascularis thickness is decreased after insult}

Administration of a single dose of the loop diuretic bumetanide is known to cause extensive edema in the stria $1 \mathrm{~h}$ after injection, but this resolves itself rapidly and abnormalities are not seen $24 \mathrm{~h}$ post treatment (Santi and Duvall 1979). When a loop diuretic is combined with an aminoglycoside (e.g., single injection of kanamycin followed by a single injection of bumetanide) a significant decrease in strial thickness begins as early as 7 days post treatment (Taylor et al. 2008). Specifically, Taylor and colleagues (2008) report that marked strial abnormalities are not seen in mice at $24 \mathrm{~h}$ or $2-4$ days post insult, including animals in which there is extensive OHC loss. Strial thickness was observed to decrease 7 days after treatment, with a further decrease between 4 and 12 weeks post treatment, and this was thought to be coincident with the time of IHC loss. The major cause of the thinning appeared to be due to a degeneration of marginal cells (Taylor et al. 2008). The findings reported here are harmonious with those of Taylor and colleagues, as the stria is thinned relative to controls at recovery times of 30 days and longer. The thickness of the stria in undamaged control animals (basal coil mean $=14.3 \pm 0.7 \mu \mathrm{m}$ ) is thinner than mean values reported by Taylor and colleagues (basal coil mean $=31.1 \mu \mathrm{m})$, but is more in line with values reported by Marcus et al. 2002 (basal coil mean= $20.5 \mu \mathrm{m})$ and Kamemori et al. $2002(24 \pm 5.14 \mu \mathrm{m})$. Some of these differences may be attributable to the different mouse strains used in the studies or differences in tissue processing.

In conclusion, we developed an in vivo model of the aminoglycoside-damaged mouse ear to facilitate use of transgenic and mutant mouse strains to investigate different aspects of $\mathrm{HC}$ regeneration. The lesion, induced with a combination of a single dose of 
aminoglycoside (kanamycin) followed by a loop diuretic (furosemide), results in rapid loss of virtually all of the OHCs throughout the entire cochlea by 3 days (Oesterle et al. 2008). To facilitate the development of therapies to repair long badly damaged ears, we have further developed our in vivo drug-damage model system by delineating the lesion characteristics at 1 year of recovery and investigating for SC dedifferentiation. The analysis presented here provide rare insight into long-term sequelae of $\mathrm{HC}$ loss in the adult mouse organ of Corti, showing that virtually all OHCs are missing and less than one third of the apical IHCs remain 1 year after insult. Support cell numbers are decreased in the apex without marked SC dedifferentiation, as evidenced by retention of acetylated tubulin, Sox2, and Jagged1 labeling, and presence of intracellular filament bundles.

\section{ACKNOWLEDGEMENTS}

The authors would like to thank the reviewers for their time and thoughtful comments, James Tse for strial thickness measurements, Glen MacDonald for help with ImageJ, Dale Cunningham for plastic sectioning, and Drs. Remy Pujol, Jennifer McCullar, Kelly Owens, Edwin Rubel, Cliff Hume, Jenny Stone, David Raible, and Olivia Bermingham-McDonogh for helpful conversations and comments. This research was supported by NIDCD R01 grant DC03944, NIDCD P30 grant DC04661, NICHHD P30 grant HD002274, and the Hearing Regeneration Initiative.

\section{REFERENCES}

Adam J, Myat A, Le Roux I, Eddison M, Henrigue D, Ish-Horowicz D, Lewis J. Cell fate choices and the expression of Notch, Delta and Serrate homologues in the chick inner ear: parallels with Drosophila sense-organ development. Development. 125 (23):4645-4654, 1998.

Boettger T, Hübner CA, Maier H, Rust MB, Beck FX, Jentsch TJ. Deafness and renal tubular acidosis in mice lacking the $\mathrm{K}-\mathrm{Cl}$ cotransporter Kcc4. Nature. 416(6883):874-878, 2002.

BoHNe BA. Healing of the noise damaged inner ear. In: Hirsh SK, Eldredge DH, Hirsh IJ, Silverman SR (eds) Hearing and Davis: Essays honoring Hallowel Davis. Saint Louis, Washington University Press, pp. 85-96, 1976.

Bohne BA, Rabiitt RD. Holes in the reticular lamina after noise exposure: implication for continuing damage in the organ of Corti. Hear. Res. 11(1):41-53, 1983.

Bohne BA, HARDING GW. Neural regeneration in the noise-damaged chinchilla cochlea. Laryngoscope. 102(6):693-703, 1992.

Bringmann A, Francke M, Pannicke T, Biedermann B, Kodal H, Faude F, Reichelt W, Reichenbach A. Role of glial $\mathrm{K}(+)$ channels in ontogeny and gliosis: A hypothesis based upon studies on Müller cells. Glia. 29(1):35-44, 2000.

Brooker R, Hozumi K, Lewis J. Notch ligands with contrasting functions: Jagged1 and Delta1 in the mouse inner ear. Development. 133(7):1277-1286, 2006.

Brummett RE, Bendrick T, Himes D. Comparative ototoxicity of bumetanide and furosemide when used in combination with kanamycin. J. Clin. Pharmacol. 21:628-636, 1981.
Cambray-Deakin MA, Burgoyne RD. Posttranslational modifications of alpha-tubulin: Acetylated and detyrosinated forms in axons of rat cerebellum. J. Cell Biol. 104(6):1569-1574, 1987.

Chardin S, Romand R. Regeneration and mammalian auditory hair cells. Science. 267(5198):707-711, 1995.

Chen P, Johnson JE, Zoghbi HY, Segil N. The role of Math1 in inner ear development: Uncoupling the establishment of the sensory primordium from hair cell fate determination. Development. 129(10):2495-2505, 2002.

Dechesne CJ, Rabejac D, Desmadryl G. Development of calretinin immunoreactivity in the mouse inner ear. J. Comp. Neurol. 346 (4):517-529, 1994.

Dodson HC, Bannister LH, Douek EE. Effects of unilateral deafening on the cochlear nucleus of the guinea pig at different ages. Brain Res. Dev. Brain Res. 80(1-2):261-267, 1994.

EPISKOPOU V. SOX2 functions in adult neural stem cells. Trends Neurosci. 28(5):219-221, 2005.

Forge A. Outer hair cell loss and supporting cell expansion following chronic gentamicin treatment. Hear. Res. 19:171$182,1985$.

Hackney CM, Mahendrasingam S, Penn A, Fettiplace R. The concentrations of calcium buffering proteins in mammalian cochlear hair cells. J. Neurosci. 25(34):7867-7875, 2005.

Hasson T, Mooseker MS. Porcine myosin-VI: Characterization of a new mammalian unconventional myosin. J. Cell Biol. 127 (2):425-40, 1994.

Hasson T, Heintzelman MB, Santos-Sacchi J, Corey DP, Mooseker MS. Expression in cochlea and retina of myosin VIIa, the gene product defective in Usher syndrome type 1B. Proc. Natl. Acad. Sci. U.S.A. 92(21):9815-9819, 1995.

Hasson t, Gillespie PG, Garcia JA, MacDonald RB, Zhao Y, Yee AG, MOOSEKer MS, Corey DP. Unconventional myosins in inner-ear sensory epithelia. J. Cell Biol. 137(6):1287-1307, 1997.

Hawkins JE, JR, Johnson LG. Histopathology of cochlear and vestibular ototoxicity in laboratory animals. In: Lerner SA, Matz JG, Hawkins JE, Jr (eds) Aminoglycoside Otoxicity. Boston, Little, Brown and Company, pp. 175-95, 1981.

Hume CR, Bratt DL, Oesterle EC. Expression of LHX3 and SOX2 during mouse inner ear development. Gene Expression Patterns. 7:798-807, 2007.

Izumikawa M, Batts SA, Miyazawa T, Swiderski DL, Raphael Y. Response of the flat cochlear epithelium to forced expression of Atoh1. Hear. Res. 240(1-2):52-56, 2008.

Johnsson LG. Sequence of degeneration of Corti's organ and its first-order neurons. Ann. Otol. Rhinol. Laryngol 83(3):294-303, 1974.

Johnsson LG, Hawkins JE, JR. Strial atrophy in clinical and experimental deafness. Laryngoscope. 82(7):1105-1125, 1972.

Kamemori M, Ohyama Y, Kurabayashi M, Takahashi K, Nagai R, Furuya N. Expression of Klotho protein in the inner ear. Hear. Res. 171 (1-2):103-110, 2002.

KeLley MW. Regulation of cell fate in the sensory epithelia of the inner ear. Nat. Rev. Neurosci 7(11):837-849, 2006 a.

KeLley MW. Hair cell development: commitment through differentiation. Brain Res. 1091(1):172-185, 2006b.

KerR A, SChuknecht HF. The spiral ganglion in profound deafness. Acta Otolaryngol. 65(6):586-598, 1968.

Kiernan AE, Xu J, Gridley T. The Notch ligand JAG1 is required for sensory progenitor development in the mammalian inner ear. PLoS Genet 2(1):e4, 2006.

Kim YH, Raphael Y. Cell division and maintenance of epithelial integrity in the deafened auditory epithelium. Cell Cycle. 6 (5):612-619, 2007.

Koitchev K, Guilhaume A, Cazals Y, Aran JM. Spiral ganglion changes after massive aminoglycoside treatment in the guinea pig. Counts and ultrastructure. Acta Otolaryngol 94(5-6):431438, 1982. 
Ladrech S, Wang J, Simonneau L, Puel JL, Lenoir M. Macrophage contribution to the response of the rat organ of Corti to amikacin. J. Neurosci. Res. 85(9):1970-1979, 2007.

Lawner BE, Harding GW, Bohne BA. Time course of nerve-fiber regeneration in the noise-damaged mammalian cochlea. Int. J. Dev. Neurosci. 15(4-5):601-617, 1997.

LeDizet M, Piperno G. Cytoplasmic microtubules containing acetylated alpha-tubulin in Chlamydomonas reinhardtii: spatial arrangement and properties. J. Cell Biol. 103(1):13-22, 1986.

LEONOVA EV, RAPHAEL Y. Organization of cell junctions and cytoskeleton in the reticular lamina in normal and ototoxically damaged organ of Corti. Hear. Res. 113(1-2):14-28, 1997.

L'Hernault SW, Rosenbaum JL. Chlamydomonas alpha-tubulin is posttranslationally modified by acetylation on the epsilon-amino group of a lysine. Biochemistry. 24(2):473-478, 1985.

Li L, Parkins CW, Webster DB. Does electrical stimulation of deaf cochleae prevent spiral ganglion degeneration? Hear. Res. 133 (1-2):27-39, 1999.

Li S, Price SM, Cahill H, Ryugo DK, Shen MM, Xiang M. Hearing loss caused by progressive degeneration of cochlear hair cells in mice deficient for the Barhll homeobox gene. Development. 129(14):3523-3532, 2002.

Liberman MC, KiANG NY. Acoustic trauma in cats. Cochlear pathology and auditory-nerve activity. Acta Otolaryngol. Suppl. 358:1-63, 1978.

MacDonald GH, Rubel EW. 2008 Three-dimensional imaging of the intact mouse cochlea by fluorescent laser scanning confocal microscopy after clearing with methyl salicylate and benzyl benzoate. Hear. Res. 243(1-2):1-10, 2008.

Marcus DC, Wu T, Wangemann P, Kofuji P. KCNJ10 (Kir4.1) potassium channel knockout abolishes endocochlear potential. Am. J. Physiol. Cell Physiol. 282(2):C403-C407, 2002.

Matz GJ, Wallace TH, Ward PH. The ototoxicity of kanamycin. A comparative histopathological study. Laryngoscope 75 (11):1690-1698, 1965.

McFadden SL, Ding D, Jiang H, Salvi RJ. Time course of efferent fiber and spiral ganglion cell degeneration following complete hair cell loss in the chinchilla. Brain Res. 997(1):40-51, 2004.

Montcouguiol M, Kelley MW. Planar and vertical signals control cellular differentiation and patterning in the mammalian cochlea. J. Neurosci. 23(28):9469-9478, 2003.

Morrison A, Hodgetts C, Gossler A, Hrabe de Angelis M, Lewis J. Expression of Delta1 and Serrate1 (Jagged1) in the mouse inner ear. Mech. Dev. 84(1-2):169-172, 1999.

NAdOL JB, JR, Young YS, GLYNn RJ. Survival of spiral ganglion cells in profound sensorineural hearing loss: Implications for cochlear implantation. Ann. Otol. Rhinol. Laryngol. 98(6):411-416, 1989.

Oesterle E, Campbell S, Taylor R, Forge A, Hume CR. Sox2 and Jagged 1 expression in adult mouse inner ear sensory epithelia. J. Assoc. Res. Otolaryngol. 9(1):65-89, 2008.

Oesterle EC, Sarthy PV, Rubel EW. Intermediate filaments in the inner ear of normal and experimentally damaged guinea pigs. Hear. Res. 47(1-2):1-16, 1990.

Pawlowski KS, Kikkawa YS, Wright CG, Alagramam KN. Progression of inner ear pathology in Ames waltzer mice and the role of protocadherin 15 in hair cell development. J. Assoc. Res. Otolaryngol. 7(2):83-94, 2006.

Pettingill LN, Richardson RT, Wise AK, O'Leary SJ, Shepherd RK. Neurotrophic factors and neural prostheses: Potential clinical applications based upon findings in the auditory system. EEE Trans. Biomed. Eng. 54(6 Pt 1):1138-1148, 2007.

RAPHAEL Y, AltsChULER RA. Modulation of cytoskeletal and junctional proteins during hair cell degeneration. Cell Motility and the Cytoskeleton 18:215-227, 1991.

Roberson DW, Rubel EW. Cell division in the gerbil cochlea after acoustic trauma. Am. J. Otol. 15(1):28-34, 1994.

Russell NJ, Fox KE, Brummett R RE. Ototoxic effects of the interaction between kanamycin and ethacrynic acid. Cochlear ultrastructure correlated with cochlear potentials and kanamycin levels. Acta Otolaryngol 88:369-381, 1979.

Sage C, Ventéo S, Jeromin A, Roder J, Dechesne CJ. Distribution of frequenin in the mouse inner ear during development, comparison with other calcium-binding proteins and synaptophysin. Hear. Res. 150(1-2):70-82, 2000.

SAHA S, SLePecky NB. Age-related changes in microtubules in the guinea pig organ of Corti. Tubulin isoform shifts with increasing age suggest changes in micromechanical properties of the sensory epithelium. Cell Tissue Res. 300(1):29-46, 2000.

SANTI PA, Duvall AJ, 3RD. Morphological alteration of the stria vascularis after administration of the diuretic bumetanide. Acta Otolaryngol. 88(1-2):1-12, 1979.

Sobkowicz HM, August BK, SLApNick SM. Epithelial repair following mechanical injury of the developing organ of Corti in culture: an electron microscopic and autoradiographic study. Exp. Neurol. 115(1):44-49, 1992.

SpoENdLin H. Retrograde degeneration of the cochlear nerve. Acta Otolaryngol. 79(3-4):266-275, 1975.

Spoendin H, Suter R. Regeneration in the VIII nerve. Acta Otolaryngol. 81(3-4):228-236, 1976.

Stankovic K, Rio C, Xia A, Sugawara M, Adams JC, Liberman MC, Corfas GJ. Survival of adult spiral ganglion neurons requires erbB receptor signaling in the inner ear. Neurosci. 24(40):8651-8661, 2004.

Strominger RN, Bohne BA, Harding GW. Hear. Res. 92:52-62, 1995.

Sugawara M, Corfas G, Liberman MC. Influence of supporting cells on neuronal degeneration after hair cell loss. J. Assoc. Res. Otolaryngol. 6(2):136-147, 2005.

Tannenbaum J, Slepecky NB. Localization of microtubules containing posttranslationally modified tubulin in cochlear epithelial cells during development. Cell Motil. Cytoskeleton 38(2):146-162, 1997.

TAylor RR, Nevill G, Forge A. Rapid hair cell loss: A mouse model for cochlear lesions. J. Assoc. Res. Otolaryngol. 9(1):44-64, 2008.

Terayama Y, Kaneko Y, Kawamoto K, Sakai N. Ultrastructural changes of the nerve elements following disruption of the organ of Corti. I. Nerve elements in the organ of Corti. Acta Otolaryngol. 83(34):291-302, 1977.

Terayama Y, Kaneko K, TANaka K, Kawamoto K. Ultrastructural changes of the nerve elements following disruption of the organ of Corti. II. Nerve elements outside the organ of Corti. Acta Otolaryngol. 88(1-2):27-36, 1979.

Teufert KB, Linthicum FH, Jr, Connell SS. The effect of organ of corti loss on ganglion cell survival in humans. Otol Neurotol. 27 (8):1146-1151, 2006.

Thompson WC, Asai DJ, CARney DH. Heterogeneity among microtubules of the cytoplasmic microtubule complex detected by a monoclonal antibody to alpha tubulin. J. Cell Biol. 98(3):1017-1025, 1984.

Webster DB, Webster M. Multipolar spiral ganglion neurons following organ of Corti loss. Brain Res. 244(2):356-359, 1982.

Webster M, Webster DB. Spiral ganglion neuron loss following organ of Corti loss: A quantitative study. Brain Res. 212(1):1730, 1981.

WeGner M, Stolt CC. From stem cells to neurons and glia: a Soxist's view of neural development. Trends Neurosci. 28(11):583-588, 2005.

West BA, Brummett RE, Himes DL. Interaction of kanamycin and ethacrynic acid. Severe cochlear damage in guinea pigs. Arch. Otolaryngol. 98:32-37, 1973.

WRIGHT CG. Neural damage in the guinea pig cochlea after noise exposure. A light microscopic study. Acta Otolaryngol. 82(12):82-94, 1976.

Wu WJ, Sha SH, McLaren JD, Kawamoto K, Raphael Y, Schacht J. Aminoglycoside ototoxicity in adult CBA, C57BL and BALB mice and the Sprague-Dawley rat. Hear. Res. 158(1-2):165178, 2001.

Zheng JL, GAO WQ. Analysis of rat vestibular hair cell development and regeneration using calretinin as an early marker. J. Neurosci. 17(21):8270-8282, 1997. 